\title{
Optimal Personal Bankruptcy Design: A Mirrlees Approach*
}

\author{
Borys Grochulski \\ Federal Reserve Bank of Richmond \\ borys.grochulski@rich.frb.org
}

\begin{abstract}
In this paper, we propose a theory of unsecured consumer credit and personal bankruptcy based on the optimal trade-off between incentives and insurance. We solve a fairly standard dynamic moral hazard problem, in which agents' private effort decisions influence the life-cycle profiles of their earnings. We then show how the optimal allocation of individual effort and consumption can be implemented in a market equilibrium in which agents and intermediaries repeatedly trade in secured and unsecured debt instruments, and agents obtain (restricted) discharge of their unsecured debts in bankruptcy. Surprisingly, the structure of this equilibrium and the associated restrictions on debt discharge closely match the main qualitative features of personal credit markets and bankruptcy law that actually exist in the United States.
\end{abstract}

\section{Introduction}

In this paper, we propose a theory of unsecured consumer credit and personal bankruptcy. Our theory is based on the optimal trade-off between incentives and insurance. Provision of insurance to "the honest but unfortunate debtor" is recognized in both the legal and economic literatures as the main role for the institution of personal bankruptcy. ${ }^{1}$ Taking this role as given, we ask the following question: How should the institution of personal bankruptcy be designed to fulfil this role efficiently?

We approach this question in two steps. In the first step, we propose an economic environment which determines what efficient provision of insurance means. Specifically, we consider a dynamic moral hazard environment in which agents' private effort decisions influence the life-cycle profiles

* Preliminary and incomplete. Comments welcome.

The views expressed here are those of the author and do not necessarily reflect those of the Federal Reserve Bank of Richmond or the Federal Reserve System.

${ }^{1}$ This role was first recognized in the 1934 Supreme Court decision Local Loan Co. v. Hunt, 292 U.S. 234,244 (1934). 
of their earnings. High effort mitigates the income risk, but cannot eliminate it completely. In this environment, the (constrained) efficient allocation of consumption and effort, as usual in moral hazard models, recommends high effort and does not provide full insurance against the income risk, as incentives for high effort must be provided through a positive correlation between income and consumption.

In the second step, we demonstrate how this solution to the moral hazard problem can be implemented as an equilibrium outcome of a market system in which agents (consumers) repeatedly trade with free-entry financial intermediaries in a set of unsecured debt instruments. Unsecured consumer debt is subject to discharge under specific rules of a personal bankruptcy law, which we characterize. Since it implements the efficient amount of income risk insurance, this bankruptcy law fulfils efficiently the role assigned to the institution of bankruptcy.

The bankruptcy law and the structure of the unsecured credit markets that we obtain as an efficient mechanism in an abstract moral hazard model turn out to closely match the main qualitative features of the bankruptcy law and personal credit markets that actually exist in the United States. First, the efficient bankruptcy law of the model consists of 1) an income-tested bankruptcy eligibility condition, and 2) an asset exemption level specifying the value of assets that consumers in bankruptcy can protect from their unsecured creditors. Both of these are features of the U.S. personal bankruptcy law. Second, the unsecured credit market arrangement obtained in the model is similar to unsecured credit markets functioning in the U.S. economy. In the model, intermediaries offer unsecured lines of credit to consumers. The conditions of these offers depend on consumers' past income and wealth data. The pricing of credit on each of these lines is non-linear in credit usage. Extensive usage is associated with more risk to the intermediaries, and triggers hikes in the interest rate. In order to correctly assess this risk, the intermediaries pool information about unsecured indebtedness of each consumer. All of these features, obtained in our model, are observed in the functioning of unsecured consumer credit markets in the United States.

The consistency of the prescriptions of our model with observed institutions suggests that the basic premise of our analysis (bankruptcy provides insurance) and our choice of the model environment (dynamic moral hazard) are correct. The prescriptions for optimal bankruptcy policy obtained in the model can therefore guide applied research aimed at finding possible inefficiencies in the personal bankruptcy regulations that are currently used. For example, the optimal bankruptcy eligibility test of the model is based solely on income, not on the amount of unsecured debt of an agent. The means test for Chapter 7 bankruptcy eligibility introduced to the U.S. code in 2005, inconsistent with the prescriptions of our model, does take the amount of debt into account. This suggests that the current means test may be inefficient. In fact, the current test admits into Chapter 7 bankruptcy agents with more debt and reject those with less, ceteris paribus, on grounds of the greater ability of 
those with less debt to repay a given fraction of their obligation. This feature of the means test can provide an incentive for agents to over-accumulate unsecured debt in order to qualify for discharge under Chapter 7 of the current law.

Our results can also serve as a guide for work aimed at matching quantitatively the main facts about consumer bankruptcy in the United States. In particular, the pricing of unsecured debt of a consumer in our model depends in an essential way on the amount of wealth held by this consumer, as wealth implicitly collateralizes nominally unsecured debt. The existing quantitative literature, to our knowledge, does not allow for this form of pricing by the intermediaries. Our results, therefore, suggest that incorporating this possibility could improve the quantitative performance of these models.

Relation to the literature Methodologically, this paper is closely related to the Mirrleesian optimal taxation literature [e.g., Kocharlakota (2005), and, especially, Albanesi and Sleet (2006)]. In this paper, we follow the same approach to the question of optimal design of the bankruptcy code as that literature uses with regard to the question of optimal design of the tax code. In this approach, following the seminal paper by James Mirrlees (1971), optimal institutions are derived as mechanisms that implement private information optima.

In the choice of the policy question, however, our paper is related to the quantitative bankruptcy reform literature. Papers in this literature include Athreya (2002), Athreya and Simpson (2006), Chatterjee et al (2005), Li and Sarte (2006), and Livshits, MacGee and Tertilt (2006). As mentioned before, our paper is complementary to the papers in this literature.

Organization Section 2 lays out the environment and defines efficiency. Section 3 provides a partial characterization of the optimal allocation. Section 4 defines implementation, lays out the market arrangement with unsecured credit, and introduces an institution of bankruptcy into the model. It also proves the implementation.

\section{Environment and efficiency}

The time horizon is finite with $T+1$ periods indexed by $t=1, \ldots, T+1$. The model economy is populated by the continuum of agents initially heterogenous only with respect to their promised utility. The social planning problem is the one of delivering this utility to the agents efficiently.

\subsection{Individual income and preferences}

All agents are identical with respect to their individual income processes and preferences. 
An agent's individual income in period $t=1, \ldots, T$, denoted by $y_{t}$, takes on values from the set $\Theta_{t}:$

$$
y_{t} \in \Theta_{t}=\left\{\theta_{t}^{L}, \theta_{t}^{H}\right\}
$$

with $\theta_{t}^{L}<\theta_{t}^{H}$ for $t=1, \ldots, T$. Agents obtain no income in the final time period $T+1$, i.e., $y_{T+1}=0$ by assumption.

Individual effort in period $t=1, \ldots, T$, denoted by $x_{t}$, takes on values from the set $\{0,1\}$ :

$$
x_{t} \in\{0,1\}
$$

for $t=1, . ., T$.

The distribution of individual income in period $t$ depends on the current effort and the last period's income level. The probability that individual income $y_{t}$ is realized at the value $\theta_{t}^{H}$ is denoted by

$$
\pi_{t}\left(\theta_{t}^{H} \mid x_{t}, y_{t-1}\right)
$$

We assume that effort is productive:

$$
\pi_{t}\left(\theta_{t}^{H} \mid 1, y_{t-1}\right)>\pi_{t}\left(\theta_{t}^{H} \mid 0, y_{t-1}\right)
$$

for all $y_{t-1}$, and allow for persistence in the income process:

$$
\pi_{t}\left(\theta_{t}^{H} \mid x_{t}, \theta_{t-1}^{H}\right) \geq \pi_{t}\left(\theta_{t}^{H} \mid x_{t}, \theta_{t-1}^{L}\right)
$$

for all $x_{t}$, with $y_{0}$ standing for the empty history.

Note that $\Theta_{t} \neq \Theta_{s}$ for $t \neq s$ allows for life-cycle effects.

Let $y^{t}=\left(y_{1}, \ldots, y_{t}\right)$ denote the length- $t$ (partial) history of realized income. Denoting the set of all income histories of length $t$ by $\Theta^{t}$, we have $\Theta^{t}=\Theta_{1} \times \ldots \times \Theta_{t}$.

An individual consumption allocation is $c=\left(c_{1}, \ldots, c_{T+1}\right)$, where $c_{t}: \Theta^{t-1} \rightarrow \mathbb{R}_{+}$, with $\Theta^{0}$ denoting the initial empty history $y_{0}$. Here, $c_{t}\left(y^{t-1}\right)$ represents the consumption assigned in period $t$ to an agent whose individual income history prior to $t$ is $y^{t-1}$.

An individual effort assignment is $x=\left(x_{1}, \ldots, x_{T}\right)$, where $x_{t}: \Theta^{t-1} \rightarrow\{0,1\}$. Here, $x_{t}\left(y^{t-1}\right)$ represents the effort recommended in period $t$ to an agent whose individual income history is $y^{t-1}$.

Let $E_{x}$ denote the expectation operator over the paths $y^{T} \in \Theta^{T}$ conditional on effort $x$.

Agents' preferences over pairs $(c, x)$ are represented by the expected utility function

$$
\mathcal{U}(c, x):=E_{x}\left[\sum_{t=1}^{T} \beta^{t-1}\left\{V_{t}\left(x_{t}\right)+U\left(c_{t}\right)\right\}+\beta^{T} U_{T+1}\left(c_{T+1}\right)\right],
$$


where $U^{\prime}>0, U^{\prime \prime}<0, U_{T}^{\prime}>0, U_{T}^{\prime \prime}<0, V_{t}^{\prime}<0$.

\subsection{Allocations}

Agents are heterogeneous with respect to their promised utility value $w_{1}$. Let $\Omega_{1}$ denote the distribution of agents with respect to the premised utility value $w_{1}$, and let $S\left(\Omega_{1}\right) \subset \mathbb{R}$ denote the support of this distribution.

A (type-identical) allocation, is an assignment of a pair $(c, x)$ to each promised utility value $w_{1}$ in $S\left(\Omega_{1}\right)$. (All agents with the same $w_{1}$ receive the same treatment.) We will denote an allocation by $A=\left(c\left(w_{1}\right), x\left(w_{1}\right)\right)_{w_{1} \in S\left(\Omega_{1}\right)}$.

An allocation delivers the promised utility distribution $\Omega_{1}$ if

$$
\mathcal{U}\left(c\left(w_{1}\right), x\left(w_{1}\right)\right)=w_{1}
$$

for all $w_{1} \in S\left(\Omega_{1}\right)$.

\subsection{Information}

Effort $x$ is agents' private information. For this reason (by the Revelation Principle this is actually sufficient) we impose the following incentive compatibility constraint.

Allocation $A$ is incentive compatible (IC) if

$$
x\left(w_{1}\right) \in \arg \max _{\tilde{x} \in \mathcal{E}} \mathcal{U}\left(c\left(w_{1}\right), \tilde{x}\right)
$$

for all $w_{1} \in S\left(\Omega_{1}\right)$, where $\mathcal{E}$ is the set of all individual effort strategies, i.e., the (finite) set of all mappings $\tilde{x}_{t}: \Theta^{t-1} \rightarrow\{0,1\}$ for $t=1, \ldots, T$.

\subsection{Constrained efficient allocations}

Allocation $A$ is (constrained) efficient if it is IC, if it provides the initial distribution of promised utility $\Omega_{1}$, and if it minimizes (among all IC allocations that attain the initial distribution $\Omega_{1}$ ) the cost of the provision of $\Omega_{1}$ given by

$$
\int_{S\left(\Omega_{1}\right)} E_{x\left(w_{1}\right)}\left[\sum_{t=1}^{T+1}\left(\Pi_{s=1}^{t-1} q_{s}\right)\left\{c_{t}\left(w_{1}\right)-y_{t}\right\}\right] \Omega_{1}\left(d w_{1}\right)
$$

where $\left\{q_{t}\right\}_{t=1}^{T}$ is an exogenous sequence of 1-period discount rates, with $\Pi_{s=1}^{0} q_{s}=1$, and where $y_{T+1}=0$.

Let $C_{1}^{*}\left(\Omega_{1}\right)$ denote the minimum cost and let $A^{*}$ denote an allocation that attains $C_{1}^{*}\left(\Omega_{1}\right)$. 
The social planning problem (in a sequence formulation) is defined as the problem of finding $C_{1}^{*}\left(\Omega_{1}\right)$ and $A^{*}$ that attains it.

\subsection{Recursive formulation of the social planning problem}

A utility allocation rule is a sequence of functions $\left(v_{t}, u_{t}, w_{t+1}\right)$ for $t=1, \ldots, T$ and a function $u_{T+1}$ such that

$$
\begin{aligned}
v_{t}: \mathbb{R} \times \Theta_{t-1} & \rightarrow V_{t}(\{0,1\}), \\
u_{t}: \mathbb{R} \times \Theta_{t-1} & \rightarrow U\left(\mathbb{R}_{+}\right), \\
w_{t+1}: \mathbb{R} \times \Theta_{t-1} \times \Theta_{t} & \rightarrow \mathbb{R},
\end{aligned}
$$

and

$$
u_{T+1}: \mathbb{R} \rightarrow U_{T+1}\left(\mathbb{R}_{+}\right) .
$$

The pair $\left(w_{t}, y_{t-1}\right)$ is a state vector that characterizes an agent at the beginning of period $t$. The value $w_{t}$ represents the continuation utility that must be delivered to the agent from $t$ onward. The variable $v_{t}\left(w_{t}, y_{t-1}\right)$ is the recommended effort utility in period $t$ for those agents whose state vector entering period $t$ is $\left(w_{t}, y_{t-1}\right)$. Similarly, $u_{t}\left(w_{t}, y_{t-1}\right)$ represents consumption utility assigned in period $t$ to those whose state entering period $t$ is $\left(w_{t}, y_{t-1}\right)$. The law of motion for the state vector consists of the transition for the income process, defined by the conditional distributions $\pi_{t+1}$, and a law of motion $w_{t+1}\left(w_{t}, y_{t-1}, y_{t}\right)$ for the continuation utility, which assigns the continuation $w_{t+1}$ to those agents whose state entering period $t$ is $\left(w_{t}, y_{t-1}\right)$ and whose realized income in period $t$ is $y_{t}$.

\subsubsection{Component planning problem}

Let $C:=U^{-1}, C_{T+1}:=U_{T+1}^{-1}$, and $X_{t}:=V_{t}^{-1}$ for $t=1, \ldots, T$.

The component planning problem is to find a family of cost functions $B_{t, y_{t-1}}: \mathbb{R} \rightarrow \mathbb{R}$ (one for each pair $\left(t, y_{t-1}\right)$ with $\left.t=1, \ldots, T+1, y_{t-1} \in \Theta_{t-1}\right)$ that solve the following recursive optimization problem

$$
B_{t, y_{t-1}}(w)=\min _{u, v, w^{\prime}\left(y_{t}\right)} C(u)+\sum_{y_{t} \in \Theta_{t}} \pi_{t}\left(y_{t} \mid X_{t}(v), y_{t-1}\right)\left\{-y_{t}+q_{t} B_{t+1, y_{t}}\left(w^{\prime}\left(y_{t}\right)\right)\right\}
$$

subject to: 
i. the temporary incentive compatibility (TIC) constraint

$$
v+\beta \sum_{y_{t} \in \Theta_{t}} \pi_{t}\left(y_{t} \mid X_{t}(v), y_{t-1}\right) w^{\prime}\left(y_{t}\right) \geq \tilde{v}+\beta \sum_{y_{t} \in \Theta_{t}} \pi_{t}\left(y_{t} \mid X_{t}(\tilde{v}), y_{t-1}\right) w^{\prime}\left(y_{t}\right)
$$

where $\tilde{v}=V_{t}\left(1-X_{t}(v)\right)$,

ii. the promise keeping $(\mathrm{PK})$ constraint

$$
v+u+\beta \sum_{y_{t} \in \Theta_{t}} \pi_{t}\left(y_{t} \mid X_{t}(v), y_{t-1}\right) w^{\prime}\left(y_{t}\right)=w
$$

and with the last period's cost function given by

$$
B_{T+1, y_{T}}(w)=\min _{u} C_{T+1}(u)
$$

subject to the promise-keeping constraint

$$
u=w
$$

In this problem, the value $B_{t, y_{t-1}}\left(w_{t}\right)$ represents the minimum resource cost at $t$ to provide the promised utility $w_{t}$ to an agent whose last period's income is $y_{t-1} .^{2}$

Note that the date- $t$ cost of resources to be delivered at $t+1$ is exogenously given by $q_{t}$. I.e., the society has access to the riskless borrowing and lending in outside markets in which the gross rate of interest $1 / q_{t}$ is determined independently of how much this society borrows or lends. ${ }^{3}$

The optimal policies in this recursive minimization problem, i.e., the policies that attain $B_{t, y_{t-1}}\left(w_{t}\right)$ in each state $\left(t, y_{t-1}, w_{t}\right)$ define a utility allocation rule, which we will denote by $\left\{\left(v_{t}^{*}, u_{t}^{*}, w_{t+1}^{*}\right)_{t=1}^{T}, u_{T+1}^{*}\right\}$.

Also, the optimal law of motion for the continuation utility $w_{t+1}^{*}\left(w_{t}, y_{t-1}, y_{t}\right)$ and the initial distribution of promised utility $\Omega_{1}$ generate a sequence of conditional promised utility distributions $\left\{\Omega_{t, y-1}\right\}_{t=2}^{T+1}$, which represent the optimal cross-sections of continuation utility for agents with lastperiod's income $y_{t-1} \in \Theta_{t-1}$.

\subsection{Duality}

The following lemma is a version of the standard duality result.

Lemma 1 Let $B_{t, y_{t-1}}$ be the component planner cost functions, and let $\left\{\left(v_{t}^{*}, u_{t}^{*}, w_{t+1}^{*}\right)_{t=1}^{T}, u_{T+1}^{*}\right\}$ be

\footnotetext{
${ }^{2}$ The notation $B_{t, y_{t-1}}\left(w_{t}\right)$ reflects the fact the state variables $t$ and $y_{t-1}$ are effectively exogenous, while $w_{t}$. is the endogenous state variable. To be precise, income $y_{t}$ is an exogenous state variable under Assumption 1 that follows.

${ }^{3}$ These outside markets do not have to be interpreted as international credit markets. They can be domestic markets in which the interest rate is determined by the marginal productivity of capital in the business sector. Production and capital accumulation processes are outside of the model, i.e., our economy represents the consumer sector for which the intertemporal resource prices are exogenous.
} 
the associated utility allocation rule. Let $A^{*}$ and $C_{1}^{*}\left(\Omega_{1}\right)$ be the efficient allocation and the minimum cost function from the sequential social planning problem. Then,

$$
E_{x^{*}\left(w_{1}\right)}\left[\sum_{t=1}^{T} \beta^{t-1}\left\{V_{t}\left(x_{t}^{*}\left(w_{1}\right)\right)+U\left(c_{t}^{*}\left(w_{1}\right)\right)\right\}+U_{T+1}\left(c_{T+1}^{*}\left(w_{1}\right)\right)\right]=w_{1}
$$

for all $w_{1}$,

$$
E_{x^{*}\left(w_{1}\right)}\left[\sum_{s=t+1}^{T} \beta^{t+1-s}\left\{V_{s}\left(x_{s}^{*}\left(w_{1}\right)\right)+U\left(c_{s}^{*}\left(w_{1}\right)\right)\right\}+U_{T+1}\left(c_{T+1}^{*}\left(w_{1}\right)\right) \mid y^{t}\right]=w_{t+1}^{*}\left(w_{t}^{*}, y_{t}\right),
$$

for $t=1, \ldots T$, and

$$
\begin{aligned}
x_{t}^{*}\left(w_{1}, y^{t-1}\right) & =X_{t}\left(v_{t}^{*}\left(w_{t}^{*}, y_{t-1}\right)\right), \\
c_{t}^{*}\left(w_{1}, y^{t-1}\right) & =C\left(u_{t}^{*}\left(w_{t}^{*}, y_{t-1}\right)\right),
\end{aligned}
$$

for all $w_{1}, y^{t}$ and $t=1, \ldots T$, and

$$
c_{T+1}^{*}\left(w_{1}, y^{T}\right)=C_{T+1}\left(u_{T+1}^{*}\left(w_{T+1}^{*}\right)\right),
$$

and

$$
C_{1}^{*}\left(\Omega_{1}\right)=\int_{S\left(\Omega_{1}\right)} B_{1, y_{0}}\left(w_{1}\right) \Omega_{1}\left(d w_{1}\right)
$$

By this lemma, the efficient allocation can be found by solving the recursive component planning problem. The solution to the recursive problem allows us to express (with a minor abuse of notation) the optimal allocation recursively as follows

$$
\begin{aligned}
& x_{t}^{*}\left(w_{t}, y_{t-1}\right)=X_{t}\left(v_{t}^{*}\left(w_{t}, y_{t-1}\right)\right), \\
& c_{t}^{*}\left(w_{t}, y_{t-1}\right)=C\left(u_{t}^{*}\left(w_{t}, y_{t-1}\right)\right),
\end{aligned}
$$

where $w_{t}$ follows the optimal law of motion determined by the efficient utility allocation rule.

\section{Properties of the optimum}

To avoid dealing with trivial cases, we assume that high effort is efficient at all dates and states.

Assumption 1 The parameters of the environment are such that high effort is efficient at all dates and states, i.e.,

$$
x_{t}^{*}\left(w_{0}, y^{t-1}\right)=1
$$


for all $t=1, \ldots, T$ and $y^{t-1} \in \Theta^{t-1}$.

Given the flexibility of the specification of preferences, technology and the support of the initial distribution $\Omega_{1}$, it is clear that such parameters actually exist. Also, it will be clear ex post that none of our results depend on this assumption.

In the recursive notation, Assumption 1 states that $v_{t}^{*}\left(w_{t}, y_{t-1}\right)=V_{t}(1)$, or, equivalently, $x_{t}^{*}\left(w_{t}, y_{t-1}\right)=1$ for all $\left(t, y_{t-1}\right)=\{1, \ldots, T\} \times \Theta_{t-1}$ and all $w_{t} \in S\left(\Omega_{t, y-1}\right)$. We maintain Assumption 1 throughout.

The following lemma establishes, as a consequence of Assumption 1, a simple property of the solution to the component planner problem, which will be useful later

Lemma 2 At any $\left(t, y_{t-1}\right)=\{1, \ldots, T\} \times \Theta_{t-1}$ and $w_{t} \in S\left(\Omega_{t, y-1}\right)$, we have

$$
w_{t+1}^{*}\left(w_{t}, y_{t-1}, \theta_{t}^{H}\right)>w_{t+1}^{*}\left(w_{t}, y_{t-1}, \theta_{t}^{L}\right)
$$

and

$$
-\theta_{t}^{H}+q_{t} B_{t, \theta_{t-1}^{H}}\left(w_{t+1}^{*}\left(w_{t}, y_{t-1}, \theta_{t}^{H}\right)\right) \leq-\theta_{t}^{L}+q_{t} B_{t, \theta_{t-1}^{L}}\left(w_{t+1}^{*}\left(w_{t}, y_{t-1}, \theta_{t}^{L}\right)\right) .
$$

Proof In Appendix.

Inequality (5) means that agents continuation value increases with realized income. This property follows from the need to reward high effort. If it did not hold, high effort would not be incentive compatible for the agents. Inequality (6) means that the component planner provides a net payment to the low-income agents and receives a net payment from the high income agents. If this were not true, the high effort recommendation would not be optimal for the planner.

Lemma 3 The cost functions $B_{t, y_{t-1}}$ are strictly increasing, strictly convex, and differentiable with

$$
B_{t, \theta_{t-1}^{H}} \leq B_{t, \theta_{t-1}^{L}}
$$

for all $t=1, \ldots, T+1$. The solution to the recursive planning problem satisfies:

$$
\begin{gathered}
B_{t, y_{t-1}}^{\prime}\left(w_{t}\right)=C^{\prime}\left(u_{t}^{*}\left(w_{t}, y_{t-1}\right)\right), \\
B_{t+1, \theta_{t}^{L}}^{\prime}\left(w_{t+1}^{*}\left(w_{t}, y_{t-1}, \theta_{t}^{L}\right)\right) q_{t} \beta^{-1}<B_{t, y_{t-1}}^{\prime}\left(w_{t}\right), \\
B_{t+1, \theta_{t}^{H}}^{\prime}\left(w_{t+1}^{*}\left(w_{t}, y_{t-1}, \theta_{t}^{H}\right)\right) q_{t} \beta^{-1}>B_{t, y_{t-1}}^{\prime}\left(w_{t}\right), \\
q_{t} \beta^{-1} \sum_{y_{t} \in \Theta_{t}} \pi_{t}\left(y_{t} \mid x_{t}^{*}, y_{t-1}\right) B_{t+1, y_{t}}^{\prime}\left(w_{t+1}^{*}\left(w_{t}, y_{t-1}, y_{t}\right)\right)=B_{t, y_{t-1}}^{\prime}\left(w_{t}\right),
\end{gathered}
$$

for all $\left(t, y_{t-1}\right)=\{1, \ldots, T\} \times \Theta_{t-1}$ and all $w_{t} \in S\left(\Omega_{t, y-1}\right)$. 


\section{Proof In Appendix.}

Directly from this lemma, we obtain the following two important properties of the optimum:

Proposition 1 At the optimum, all agents are

1. insurance-constrained:

$$
\begin{aligned}
\beta U^{\prime}\left(c_{t+1}^{*}\left(w_{t+1}^{*}\left(w_{t}, y_{t-1}, \theta_{t}^{H}\right), \theta_{t}^{H}\right)\right) & <q_{t} U^{\prime}\left(c_{t}^{*}\left(w_{t}, y_{t-1}\right)\right) \\
& <\beta U^{\prime}\left(c_{t+1}^{*}\left(w_{t+1}^{*}\left(w_{t}, y_{t-1}, \theta_{t}^{L}\right), \theta_{t}^{L}\right)\right)
\end{aligned}
$$

for all $t=1, \ldots T$ and $y_{t-1} ;$ and

2. savings-constrained:

$$
\frac{U^{\prime}\left(c_{t}^{*}\left(w_{t}, y_{t-1}\right)\right)}{\sum_{y_{t} \in \Theta_{t}} \pi_{t}\left(y_{t} \mid x_{t}^{*}, y_{t}\right) \beta U^{\prime}\left(c_{t+1}^{*}\left(w_{t+1}^{*}\left(w_{t}, y_{t-1}, y_{t}\right), y_{t}\right)\right)}<\frac{1}{q_{t}}
$$

for all $t=1, \ldots, T$ and $y_{t-1}$.

The inequality (12) means that the optimal amount of insurance provided to the agents is lessthan-full. At the optimal allocation, if an agent had an opportunity to take out insurance against the consumption risk remaining in the optimal consumption allocation, she would be willing to pay more than the fair-odds premium for it.

The inequality (14) means that the optimal amount of intertemporal consumption-smoothing provided to the agents is less-than-full. At the optimal allocation, if an agent had an opportunity to alter the optimal consumption pattern by borrowing or saving, she would be willing to save at the gross rate of interest smaller than $1 / q_{t}$.

\section{Market equilibrium and implementation}

We proceed now to showing how the optimum can be implemented as an equilibrium outcome of a market system in which agents sequentially trade with zero-profit intermediaries in secured and unsecured debt instruments subject to debt discharge regulated by an institution similar to the U.S. bankruptcy law.

As a point of departure, we consider a result of Atkeson and Lucas (1992), which demonstrates that the standard riskless bond market equilibrium is incapable of the implementation of the private information optimum. To this end, consider, in the context of our life-cycle moral hazard environ- 
ment, the market mechanism consisting simply of markets for the riskless bond. ${ }^{4}$ With free entry into the riskless borrowing and lending, the presence of the outside markets for riskless claims with prices $\left\{q_{t}\right\}_{t=1}^{T}$ implies (by arbitrage) that the equilibrium bond prices must be identically equal to $\left\{q_{t}\right\}_{t=1}^{T}$. An equilibrium allocation of consumption under such a set of markets, denote it by $\hat{c}$, must satisfy the standard Euler equation

$$
U^{\prime}\left(\hat{c}_{t}\right) q_{t}=\beta E_{t}\left[U^{\prime}\left(\hat{c}_{t+1}\right)\right] .
$$

Therefore, $\hat{c}$ cannot coincide with $c^{*}$, as $c^{*}$ satisfies the strict inequality (14), which can be rewritten as

$$
U^{\prime}\left(c_{t}^{*}\right) q_{t}<\beta E_{t}\left[U^{\prime}\left(c_{t+1}^{*}\right)\right]
$$

This, as pointed out in Atkeson and Lucas (1992), means that a simple set of riskless claims markets does not implement the private-information optimum. ${ }^{5}$

Intuitively, two factors contribute to the riskless claims markets' failure to implement the optimum. First, riskless claims do not provide payoffs contingent on individual-specific states, i.e., the riskless bond (secured credit) markets do not allow the agents to sufficiently insure their income risk. Second, riskless claims markets provide unrestricted access to self-insurance via savings. In the presence of the first failure, agents over-self-insure (i.e., over-save) in the riskless claims equilibrium.

In the market arrangement that we formally define in the next subsection, competitive intermediaries extend unsecured credit to the agents, which provides the agents with insurance against individual income risk superior to self-insurance. Unsecured debt instruments, in conjunction with appropriately restricted debt discharge in bankruptcy, constitute assets whose payoffs are contingent on agents' individual income realizations. This contingency of the unsecured debt payoffs is achieved by making dischargeability of unsecured debt obligations contingent on the low realization of individual income. In bankruptcy, low-income agents receive discharge of their unsecured debt obligations, which have to be written off by the intermediaries as losses. This makes for an implicit transfer from the intermediaries to the low-income agents. High-income agents, however, by design of the bankruptcy law, are ineligible for bankruptcy. They must repay the unsecured obligations with interest. The interest on the unsecured debt (the default premium) constitutes a profit for the intermediaries, i.e. an implicit transfer from the high-income agents to the intermediaries. The equilibrium default premium on unsecured credit is determined at the level at which the intermediaries break even (make zero profit). Thus, this pattern of unsecured borrowing and income-contingent

\footnotetext{
${ }^{4}$ Lending in this debt instrument is riskless, as the promise to repay is secured by an external enforcement mechansim. We thus identify the riskless bond with secured debt.

${ }^{5}$ In the above, $E_{t}$ denotes the expectation conditional on information available at the beginning of period $t$, i.e., $E_{t}\left[U^{\prime}\left(c_{t}\right)\right]$ is $y^{t-1}$-measurable.
} 
discharge implements a transfer from the high-income agents to the low-income agents, i.e., provides insurance, which helps resolve the first failure of the riskless bond equilibrium.

The second failure (over-self-insurance) is resolved by designing the bankruptcy law in such a way that the benefit of the bankruptcy discharge is tied to not over-saving. In equilibrium, agents can freely save, i.e., accumulate wealth by buying riskless claims in any quantity they want and can afford. Excessive amounts of wealth, however, cannot be retained by agents who seek discharge of their unsecured debt obligations in bankruptcy. This, effectively, makes dischargeability of the nominally unsecured debt conditional on the debtor's wealth, in a way that eliminates the benefit of the bankruptcy option for over-savers. Agents are free to save, but they value the option of discharge. This discourages over-saving, and eliminates the second failure of the riskless bond equilibrium. What exactly constitutes an over-saving follows from the optimal amount of "savings" implicit in the optimal allocation $c^{*}$.

Since the payoff of a riskless claim is not contingent on any agent's income realization, there is no way for the agents to privately influence the riskless bond's payoff structure, and, therefore, the pricing of this bond is straightforward. Unsecured debt, however, is harder to price. Since the payoff of an unsecured debt contract depends on the individual income of the issuer (through the possibility of discharge in bankruptcy if income is low), the borrower can take a private (unobservable to the lender) action (effort) to influence this contract's payoff structure. In order to price unsecured credit correctly, a lender must form a correct expectation of the borrower's effort. In equilibrium that we study in the next section, the lenders can in fact do this because the asset position of the borrower and his preferences are publicly observable. Given an asset position of the borrower, the lender can correctly predict the borrower's effort by solving the borrower's utility maximization problem. In equilibrium, this results with non-linear pricing of unsecured credit. Unsecured debt issued by a borrower is priced favorably as long as the overall asset position of the borrower is consistent with high effort. Such asset positions are characterized by low levels of unsecured debt. If the borrower takes out a large amount of unsecured credit, the lenders' believe that, the borrower must expect to go bankrupt (and obtain discharge of this large obligation) with high likelihood, which makes the unsecured debt issued by this borrower more risky, which, in turn, necessitates a hike in pricing.

In the next section, we show formally how this market structure, together with the abovedescribed legal arrangement concerning dischargeability, implements the optimal allocation as a market equilibrium, thus making this market arrangement optimal. The main point of the paper, which we argue for in the following section, is that the market/legal arrangement obtained as optimal in our model bears a close resemblance to the functioning of the actual unsecured credit markets and the institution of personal bankruptcy in the US. 


\subsection{Unsecured credit markets and bankruptcy discharge conditions}

The timing of interaction in the market mechanism is as follows. At the beginning of each period $t=1, \ldots, T+1$ each agent is characterized by her wealth (stock of riskless claims she holds) $b_{t}$ and last period's income data $y_{t-1}$. The timing of events within the period is divided into three stages.

Stage 1 In the first stage within period $t$, intermediaries offer unsecured credit to the agents, agents make decisions on how much unsecured credit to take out, $h_{t} \geq 0$. Bonds $b_{t}$ mature, and agents decide on how allocate their resources $b_{t}+h_{t}$ between consumption $c_{t}$ and savings $s_{t}$. At this point, also, agents expend their effort $x_{t}$. The unsecured credit available to agents comes as a loan offer extended to the agents by the intermediaries. This loan is short-term: it matures within period $t$, at stage 2 , after agents receive their income $y_{t}$. The choice of the unsecured loan size $h_{t}$ that agents decide to take out is publicly observable (unlike the choice of effort $x_{t}$, which is private). The gross interest rate on the loans offered by the intermediaries is a non-linear schedule $R_{t, y_{t-1}}\left(h_{t}, b_{t}\right)$. The pricing is a part of the loan offer, i.e., is known to the agents before they decide on $h_{t}$ (or $x_{t}$ ). Thus, at the end of stage 1 , an agent initially characterized by wealth $b_{t}$ and past income data $y_{t-1}$ holds assets $s_{t}=b_{t}+h_{t}-c_{t}$, owes $R_{t, y_{t-1}}\left(h_{t}, b_{t}\right) h_{t}$ to the intermediaries, and has expended privately effort $x_{t} \in\{0,1\}$. Note that each agent holds both assets $s_{t}$ and liabilities $R_{t, y_{t-1}} h_{t}$, i.e., wealth $s_{t}$ is leveraged by debt $R_{t, y_{t-1}} h_{t}$ (in contrast to beginning of period wealth $b_{t}$ ).

Stage 2 In the second stage within the period, individual income $y_{t}$ is realized, and the unsecured loans $h_{t}$ are due. At this stage, each agent chooses how to settle their unsecured debt obligation. There are, potentially, two options: to pay back, or to default and seek discharge in bankruptcy. Let $d_{t} \in\{0,1\}$ be the indicator of the decision to default in period $t$. What happens after default is regulated by a bankruptcy law, which is specified as follows. First, there is a bankruptcy eligibility condition $f_{t}$, which specifies that only low-income agents are eligible for discharge of debt in bankruptcy. By this condition, the repayment of high-income agents' unsecured loans will be enforced (there is full enforcement in the environment we study). This effectively eliminates the choice of $d_{t}=1$ for those whose income $y_{t}$ is realized at $\theta_{t}^{H}$. Those with the low income realization $y_{t}=\theta_{t}^{L}$ meet the eligibility condition $f_{t}$, and can choose $d_{t}=1$ or $d_{t}=0$. If they choose $d_{t}=0$, they repay the loan $h_{t}$ with interest (just like the high-income agents do), i.e., they pay $R_{t, y_{t-1}}\left(h_{t}, b_{t}\right) h_{t}$ to the intermediaries. If they choose $d=1$, the settlement of their obligations is handled (by a bankruptcy court) according to the rules specified in the bankruptcy law. These rules are as follows.

1. The unsecured debt obligations of an eligible agent, $R_{t, y_{t-1}}\left(h_{t}, b_{t}\right) h_{t}$, are discharged.

2. All current and future income of the bankrupt agent is out of reach of the unsecured creditors (i.e., is exempt). 
3. The assets held by the bankrupt agent, $s_{t}$, are exempt up to a maximum $\bar{s}_{t, y-1}\left(b_{t}\right)$. Any assets in excess of the exemption level are seized from the bankrupt agent and used to (at least partially) repay the unsecured creditors.

Note that under these rules, the unrecovered portion of the unsecured debt that goes into bankruptcy has to be written off by the intermediaries as a loss. Thus, agents exit bankruptcy with income $y_{t}=\theta_{t}^{L}$, with assets given by the smaller of $s_{t}$ and $\bar{s}_{t, y-1}\left(s_{t}\right)$, and with no unsecured debt obligations. Creditors exit with profits from the repaid loans (by those agents who did not go bankrupt) and losses on the loans that got discharged (in equilibrium, these will add up to zero).

Stage 3 Finally, in the third stage, agents use their post-settlement wealth to purchase claims $b_{t+1}$, which will be their wealth entering period $t+1$.

Bankruptcy Code formalism In the model, the rule for bankruptcy eligibility and discharge are represented by the function $f_{t}$ given by

$$
f_{t}: \Theta_{t} \rightarrow\{0,1\}
$$

one for each $t=1, \ldots, T$. The asset exemption level in bankruptcy is formally represented by the function $g_{t, y_{t-1}}$

$$
g_{t, y_{t-1}}: \mathbb{R} \rightarrow \mathbb{R}
$$

for all $t$ and $y_{t-1} \in \Theta_{t-1}$. In this notation, $f_{t}\left(y_{t}\right)$ is the bankruptcy eligibility indicator for an agent whose income is $y_{t}$. The value $g_{t, y_{t-1}}\left(b_{t}\right)$, in turn, represents the non-exempt assets, i.e., the assets $s_{t}$ seized in bankruptcy from a bankrupt agent whose initial wealth entering period $t$ was $b_{t}$.

Agents' problem Agents take as given the riskless bond prices $\left\{q_{t}\right\}_{t=1}^{T}$, the unsecured loans pricing schedules $\left\{\left\{R_{t, y_{t-1}}\right\}_{y_{t-1} \in \Theta_{t-1}}\right\}_{t=1}^{T}$, and the rules of bankruptcy $\left\{f_{t},\left\{g_{t, y_{t-1}}\right\}_{y_{t-1} \in \Theta_{t-1}}\right\}_{t=1}^{T}$. Given an initial wealth level $b_{1}$, an agent solves the following recursive maximization problem:

$$
W_{t, y_{t-1}}\left(b_{t}\right)=\max _{\substack{c, x, h, s, d\left(y_{t}\right), b^{\prime}\left(y_{t}\right)}} V_{t}(x)+U(c)+\beta \sum_{y_{t} \in \Theta_{t}} \pi_{t}\left(y_{t} \mid x, y_{t-1}\right) W_{t+1, y_{t}}\left(b^{\prime}\left(y_{t}\right)\right)
$$


subject to the budget constraints

$$
\begin{aligned}
h & \geq 0 \\
c+s & =b_{t}+h \\
d\left(y_{t}\right) & \in\{0,1\} \\
d\left(y_{t}\right) & \leq f_{t}\left(y_{t}\right) \\
q_{t} b^{\prime}\left(y_{t}\right) & =y_{t}+s-\left(1-d\left(y_{t}\right)\right) R_{t, y_{t-1}}\left(h, b_{t}\right) h-d\left(y_{t}\right) g_{t, y_{t-1}}\left(b_{t}\right)
\end{aligned}
$$

for $t=1, \ldots, T$ with

$$
W_{T+1, y_{T}}\left(b_{T+1}\right)=\max _{c \leq b_{T+1}} U_{T+1}(c) .
$$

The budget constraint (15e) takes into account the consequences of bankruptcy. If $d=1$, which - by (15d) - is only feasible if $f_{t}\left(y_{t}\right)=1$, then two consequences result. On the one hand, $R_{t, y_{t-1}}\left(h, b_{t}\right) h$ is discharged. On the other hand, non-exempt assets $g_{t, y_{t-1}}\left(b_{t}\right)$ are seized.

We will denote the agents' individually optimal policies, i.e., the policies that attain the value functions $\left\{W_{t, y_{t-1}}\right\}_{t=1}^{T+1}$ by, respectively, $x_{t, y_{t-1}}\left(b_{t}\right), c_{t, y_{t-1}}\left(b_{t}\right), h_{t, y_{t-1}}\left(b_{t}\right), s_{t, y_{t-1}}\left(b_{t}\right), d_{t, y_{t-1}}\left(b_{t}, y_{t}\right)$, $b_{t+1, y_{t-1}}\left(b_{t}, y_{t}\right)$ for $t=1, \ldots, T$, and $c_{T+1}\left(b_{T+1}\right)$.

Creditors' problem Assuming that all trades in the riskless claims are made by the agents directly in the external markets, we specify now the problem of the intermediaries that extend unsecured credit to the consumers.

Intermediaries (i.e., unsecured creditors, lenders) choose the pricing schedules $R_{t, y_{t-1}}\left(h_{t}, b_{t}\right)$ for unsecured loans (lines of credit) $h_{t}$. The pricing schedule specifies the gross interest rate $R_{t, y_{t-1}}\left(h_{t}, b_{t}\right)$ within the period $t$ on the loan of size $h_{t}$ for agents whose wealth is $b_{t}$ and past income data is $y_{t-1}$. Creditors extend their offers to consumers before they know the actual demand for loans $h_{t}$. Therefore, they form an expectation $h_{t, y_{t-1}}^{e}\left(b_{t}\right)$ of the amount of unsecured credit demanded by the agents of type $y_{t-1}, b_{t}$ in period $t$. They also form an expectation $D_{t, y_{t-1}}^{e}\left(b_{t}\right)$ of the fraction of the loans of type $y_{t-1}, b_{t}$ that will be discharged in bankruptcy at the second stage of period $t$, and the expectation $\gamma_{t, y_{t-1}}^{e}\left(b_{t}\right)$ of the principal recovery rate on the bad loans of type $y_{t-1}, b_{t}$.

The period- $t$ expected profit on a loan of type $y_{t-1}, b_{t}$ of an intermediary that holds a market portfolio of consumer loans of type $y_{t-1}, b_{t}$ is given by

$$
\Pi_{t, y_{t-1}, b_{t}}^{e}=\left[-1+\left(1-D_{t, y_{t-1}}^{e}\left(b_{t}\right)\right) R_{t, y_{t-1}}\left(h_{t, y_{t-1}}^{e}\left(b_{t}\right), b_{t}\right)+D_{t, y_{t-1}}^{e}\left(b_{t}\right) \gamma_{t, y_{t-1}}^{e}\left(b_{t}\right)\right] h_{t, y_{t-1}}^{e}\left(b_{t}\right) .
$$

The objective of an intermediary is to choose a pricing schedule $R_{t, y_{t-1}}\left(h_{t}, b_{t}\right)$ under which it 
breaks even, i.e., the profit is zero. This objective for the intermediary is a reduced version of profit maximization, in the following sense: If the objective of the intermediary is to maximize profit, we get, under free entry to intermediation, that equilibrium profits are zero, due to constant returns to scale in intermediation. We thus replace the intermediaries profit maximization objective with the break-even condition.

Since in equilibrium the intermediaries make zero profits on each type of loan in every period, the number of intermediaries operating in equilibrium is indeterminate. It is important to note that the interest rate $R_{t, y_{t-1}}\left(h_{t}, b_{t}\right)$ depends on the total amount of unsecured credit $h_{t}$ that a given consumer takes out with the whole unsecured lending sector. Whatever the number of intermediaries, each lender must be able to observe the total amount of unsecured credit that a given consumer takes out with all intermediaries (no borrowing behind the back of any lender). We assume that such an observation mechanism is available to the unsecured creditors. In the environment we study, this assumption is consistent with the fundamentals, in which the only piece of consumers' private information is their individual effort.

\subsection{Equilibrium}

Definition 1 Given an initial distribution of wealth $\Psi_{1}$, the riskless bond prices $\left\{q_{t}\right\}_{t=1}^{T}$, and the rules of bankruptcy $(f, g)=\left\{f_{t},\left\{g_{t, y_{t-1}}\right\}_{y_{t-1} \in \Theta_{t-1}}\right\}_{t=1}^{T}$; competitive equilibrium with bankruptcy consists of the consumers' value functions $\left\{W_{t, y_{t-1}}\right\}_{t=1}^{T+1}$ and individual policies $\hat{x}_{t, y_{t-1}}$, $\hat{h}_{t, y_{t-1}}, \hat{c}_{t, y_{t-1}}, \hat{s}_{t, y_{t-1}}, \hat{d}_{t, y_{t-1}}, \hat{b}_{t+1, y_{t-1}}, \hat{c}_{T+1}$, the pricing schedules $\left\{\left\{R_{t, y_{t-1}}\right\}_{y_{t-1} \in \Theta_{t-1}}\right\}_{t=1}^{T}$ and expectations $h_{t, y_{t-1}}^{e}, D_{t, y_{t-1}}^{e}, \gamma_{t, y_{t-1}}^{e}$ such that

1. the value functions and policies solve the consumers' problem;

2. intermediaries' profits on every loan type are zero, i.e.,

$$
\Pi_{t, y_{t-1}, b_{t}}^{e}=0
$$

for all $t, y_{t-1}, b_{t}$;

3. expectations are correct, i.e.,

$$
\begin{aligned}
h_{t, y_{t-1}}^{e}\left(b_{t}\right) & =\hat{h}_{t, y_{t-1}}\left(b_{t}\right) \\
D_{t, y_{t-1}}^{e}\left(b_{t}\right) & =\sum_{y_{t} \in \Theta_{t}} \pi_{t}\left(y_{t} \mid \hat{x}_{t, y_{t-1}}\left(b_{t}\right), y_{t-1}\right) \hat{d}_{t, y_{t-1}}\left(b_{t}\right), \\
\gamma_{t, y_{t-1}}^{e}\left(b_{t}\right) & =\frac{g_{t, y_{t-1}}\left(\hat{s}_{t, y_{t-1}}\left(b_{t}\right)\right)}{\hat{h}_{t, y_{t-1}}\left(b_{t}\right)} \quad \text { if } \quad \hat{h}_{t, y_{t-1}}\left(b_{t}\right)>0
\end{aligned}
$$


for all $t, y_{t-1}, b_{t}$.

Let $E Q\left(\Psi_{1}, f, g\right)$ denote the set of objects that constitute an equilibrium under initial wealth distribution $\Psi_{1}$ and under the bankruptcy rules $(f, g)$.

For a given equilibrium $E Q\left(\Psi_{1}, f, g\right)$, the equilibrium policies $\hat{x}_{t, y_{t-1}}, \hat{c}_{t, y_{t-1}}, \hat{b}_{t+1, y_{t-1}}, \hat{c}_{T+1}$ imply an allocation of consumption $\hat{c}_{t}\left(b_{1}, y^{t-1}\right)$ and effort $\hat{x}_{t}\left(b_{1}, y^{t-1}\right)$ for each initial wealth level $b_{1}$ and the realized history of income shocks $y^{t}$ for $t=1, \ldots, T+1$. We will denote this equilibrium allocation (in sequential notation) by

$$
\hat{A}\left(\Psi_{1}\right)=\left(\hat{c}\left(b_{1}\right), \hat{x}\left(b_{1}\right)\right)_{b_{1} \in S\left(\Psi_{1}\right)} .
$$

\subsection{Implementation}

We now formally define implementation. Our definition is similar to the one used in Albanesi and Sleet (2006).

Recall that $A^{*}\left(\Omega_{1}\right)=\left(c^{*}\left(w_{1}\right), x^{*}\left(w_{1}\right)\right)_{w_{1} \in S\left(\Omega_{1}\right)}$ denotes an efficient allocation (in sequential notation) that attains the minimum cost of provision of the initial distribution of promised utility $\Omega_{1}$, $C_{1}^{*}\left(\Omega_{1}\right)$.

Let $\phi: \mathbb{R} \rightarrow \mathbb{R}$ be a measurable function assigning initial wealth $b_{1}$ to each initial promised utility $w_{1}$, i.e., for all $w_{1} \in S\left(\Omega_{1}\right)$ we have $\phi\left(w_{1}\right)=b_{1}$.

Definition 2 We say that a bankruptcy code $(f, g)$ and an initial wealth assignment $\phi$ implement the efficient allocation $A^{*}\left(\Omega_{1}\right)$ if there exists a competitive equilibrium with bankruptcy $E Q\left(\phi^{-1}\left(\Omega_{1}\right), f, g\right)$ such that the equilibrium allocation $\hat{A}\left(\phi^{-1}\left(\Omega_{1}\right)\right)$ coincides with the optimal allocation $A^{*}\left(\Omega_{1}\right)$, i.e., for all $w_{1} \in S\left(\Omega_{1}\right)$

$$
\begin{aligned}
& \hat{x}_{t}\left(\phi^{-1}\left(w_{1}\right), y^{t-1}\right)=x_{t}^{*}\left(w_{1}, y^{t-1}\right) \\
& \hat{c}_{t}\left(\phi^{-1}\left(w_{1}\right), y^{t-1}\right)=c_{t}^{*}\left(w_{1}, y^{t-1}\right)
\end{aligned}
$$

for all $t=1, \ldots, T$, all $y^{t}$, and

$$
\hat{c}_{T+1}\left(\phi^{-1}\left(w_{1}\right), y^{T}\right)=c_{t}^{*}\left(w_{1}, y^{T}\right) .
$$

Note that the conditions (16) and (17) imply that

$$
\int_{S\left(\Omega_{1}\right)} E_{\hat{x}\left(\phi^{-1}\left(w_{1}\right)\right)}\left[\sum_{t=1}^{T+1}\left(\Pi_{s=1}^{t-1} q_{s}\right)\left\{\hat{c}_{t}\left(\phi^{-1}\left(w_{1}\right)\right)-y_{t}\right\}\right] \Omega_{1}\left(d w_{1}\right)=C_{1}^{*}\left(\Omega_{1}\right)
$$


i.e., the amount of resources used by the equilibrium allocation $\hat{A}\left(\phi^{-1}\left(\Omega_{1}\right)\right)$ is equal to the minimum $C_{1}^{*}\left(\Omega_{1}\right)$.

Theorem 1 For any distribution of initial utility $\Omega_{1}$, there exist a bankruptcy code $(f, g)$ and the wealth assignment $\phi$ that implement the efficient allocation $A^{*}\left(\Omega_{1}\right)$. In particular, the implementation is attained by the code $(f, g)$ given by

$$
\begin{aligned}
f_{t}\left(y_{t}\right) & =\left\{\begin{array}{ccc}
1 & \text { if } & y_{t}=\theta_{t}^{L} \\
0 & \text { if } & y_{t}=\theta_{t}^{H}
\end{array},\right. \\
g_{t, y_{t-1}}\left(b_{t}\right) & =\max \left\{s_{t}-\bar{s}_{t, y_{t-1}}\left(b_{t}\right), 0\right\},
\end{aligned}
$$

with

$$
\bar{s}_{t, y_{t-1}}\left(b_{t}\right)=q_{t} B_{t+1, \theta_{t}^{L}}\left(w_{t+1}^{*}\left(B_{t, y_{t-1}}^{-1}\left(b_{t}\right), y_{t-1}, \theta_{t}^{L}\right)\right)-\theta_{t}^{L}
$$

where $B_{t+1, y_{t}}$ is the component planning cost function, $w_{t+1}^{*}$ is the optimal continuation value law of motion, and with the function $\phi$ given by

$$
\phi\left(w_{1}\right)=B_{1, y_{0}}\left(w_{1}\right)
$$

for all $w_{1} \in S\left(\Omega_{1}\right)$.

The optimal bankruptcy eligibility condition (18) states simply that only low-income agents are eligible for bankruptcy discharge. The optimal asset exemption level is given in (18). It specifies that, upon discharge of unsecured debts $R_{t, y_{t-1}}\left(h_{t}, b_{t}\right) h_{t}$, assets in excess of $\bar{s}_{t, y_{t-1}}\left(b_{t}\right)$ will be seized from the debtor. We will refer to $\bar{s}_{t, y_{t-1}}\left(b_{t}\right)$ as the exemption level for type $y_{t-1}, b_{t}$.

The specification (20) of the exemption level $\bar{s}_{t, y_{t-1}}\left(b_{t}\right)$ is key. Note that for every $t, y_{t-1}$ the mapping from wealth $b_{t}$ to the exemption level $\bar{s}_{t, y_{t-1}}\left(b_{t}\right)$ is fully determined by the (recursive) solution to the social planning problem. Specifically, it is determined by the component planner cost functions $B_{t, y_{t-1}}$, and $B_{t+1, y_{t}}$, and the optimal utility allocation rule $u_{t}^{*}, w_{t+1}^{*}$.

Before we proceed with providing a proof of this theorem, we give an informal description of the dynamic structure the optimal equilibrium $E Q\left(\phi^{-1}\left(\Omega_{1}\right), f, g\right)$.

The intertemporal structure of the equilibrium outcome Agents enter period 1 with wealth $b_{1}=B_{1, y_{0}}\left(w_{1}\right)$, i.e., with wealth equal to the planner's cost of providing the $w_{1}$ specific to them. At the first stage of within-the-period interaction, agents expend effort, consume, and borrow in the unsecured credit markets (i.e., take out nominally unsecured loans). At the second stage (the settlement stage), those with the high income realization $y_{1}=\theta_{1}^{H}$ repay the loans with interest, and those with with the low income realization $y_{1}=\theta_{1}^{L}$ go bankrupt and receive discharge. Agents enter 
the final stage of period 1 with resources free of claims from unsecured creditors (by virtue of either re-payment or discharge) and use these resources for the purchases of claims $b_{2}$. A key property of the equilibrium is that

$$
\begin{aligned}
& \hat{x}_{1}\left(b_{1}\right)=1, \\
& \hat{c}_{1}\left(b_{1}\right)=C\left(u_{1}^{*}\left(B_{1, y_{0}}^{-1}\left(b_{1}\right), y_{0}\right)\right),
\end{aligned}
$$

and

$$
\hat{b}_{2}\left(b_{1}, y_{1}\right)=B_{2, y_{1}}\left(w_{2}^{*}\left(B_{1, y_{0}}^{-1}\left(b_{1}\right), y_{0}, y_{1}\right)\right)
$$

for all $b_{1}$ and $y_{1} \in \Theta_{1}$. This means that equilibrium effort and consumption at $t=1$ replicate those prescribed by the optimal allocation rule, and that the wealth that agents with initial wealth $b_{1}$ and realized income $y_{1}$ choose to hold in equilibrium at the beginning of period 2 coincides with the component planner's cost function $B_{2, y_{1}}$ evaluated at the continuation utility that the optimal allocation rule assigns to an agent with initial promised utility $w_{1}=\phi^{-1}\left(b_{1}\right)$ and realized income $y_{1}$, i.e., $w_{2}^{*}\left(B_{1, y_{0}}^{-1}\left(b_{1}\right), y_{0}, y_{1}\right)$. Thus, equilibrium wealth $\hat{b}_{2}$ and pervious-period income data $y_{1}$ constitute an individual state vector that carries in equilibrium the same information that the individual state vector $\left(w_{2}^{*}, y_{1}\right)$ carries in the recursive optimum. The (invertable) cost function $B_{2, y_{1}}$ provides an indentifing mapping between $w_{2}^{*}$ and $\hat{b}_{2}$, conditional on $y_{1}$. From this mapping we get that the conditional distribution of wealth at the beginning of period $t=2$ is given by $B_{2, y_{1}}\left(\Omega_{2, y_{1}}\right)$ for each $y_{1} \in \Theta_{1}$.

The same transition is repeated in periods $t=2,3, \ldots, T$. Each agent's individual history is summarized by the vector $\left(\hat{b}_{t}, y_{t-1}\right)$. At each date, the optimal exemption level $\bar{s}_{t, y_{t-1}}$ is determined as in (20). The correspondence between $\left(\hat{b}_{t}, y_{t-1}\right)$ and $\left(w_{t}^{*}, y_{t-1}\right)$ is given by $\hat{b}_{t}=B_{t, y_{t-1}}\left(w_{t}^{*}\right)$. The distribution of wealth among the agents with common $y_{t-1}$ is given by $B_{t, y_{t-1}}\left(\Omega_{t, y_{t-1}}\right)$. Equilibrium consumption $\hat{c}_{t}\left(\hat{b}_{t}\right)$ for agents with last-period income data $y_{t-1}$, and their savings $\hat{b}_{t+1}\left(b_{t}, y_{t}\right)$ replicate the optimum, i.e.,

$$
\hat{c}_{t}\left(\hat{b}_{t}\right)=C\left(u_{t}^{*}\left(B_{t, y_{t-1}}^{-1}\left(\hat{b}_{t}\right), y_{t-1}\right)\right)
$$

and

$$
\hat{b}_{t+1}\left(\hat{b}_{t}, y_{t}\right)=B_{t+1, y_{t}}\left(w_{2}^{*}\left(B_{t, y_{t-1}}^{-1}\left(\hat{b}_{t}\right), y_{t-1}, y_{t}\right)\right) .
$$

Also, equilibrium effort is optimal: $\hat{x}_{t}\left(\hat{b}_{t}\right)=1$.

Transitioning this way, agents arrive at the beginning of period $T+1$ characterized by last-period's income data $y_{T} \in \Theta_{T}$ and wealth holdings $\hat{b}_{T+1}$ with

$$
\hat{b}_{T+1}=B_{T+1}\left(w_{T+1}^{*}\right)
$$


for some $w_{T+1}^{*} \in S\left(\Omega_{T+1, y_{T}}\right)$. The aggregate distribution of wealth $\hat{b}_{T+1}$ conditional on $y_{T}$ is $B_{T+1}\left(\Omega_{T+1, y_{T}}\right)$. The only decision that agents make in period $T+1$ is how much to consume, and, obviously, all choose to consume their whole wealth. In equilibrium, this wealth - equal to component planner cost at $T+1$-is just enough to fund as much consumption as the component planner delivers at the optimum:

$$
\hat{c}_{T+1}\left(\hat{b}_{T+1}\right)=C_{T+1}\left(u_{T+1}^{*}\left(w_{T+1}^{*}\right)\right) .
$$

This means that the equilibrium allocation replicates the optimal allocation at $T+1$ for all $w_{T+1}^{*} \in$ $S\left(\Omega_{T+1, y_{T}}\right)$.

In this way, the described equilibrium achieves implementation of the optimum at all dates $t=1, \ldots, T+1$.

We now prove that the outcome we described indeed is an equilibrium.

\subsection{Proof of Theorem 1}

We prove this theorem using backward induction. The first step is the following lemma.

Lemma 4 For both $y_{T} \in \Theta_{T}$,

$$
W_{T+1, y_{T}}=B_{T+1, y_{T}}^{-1}
$$

Proof Solving for $W_{T+1, y_{T}}$, from definition, we get

$$
\begin{aligned}
W_{T+1, y_{T}}\left(b_{T+1}\right) & =\max _{c_{T+1} \leq b_{T+1}} U_{T+1}\left(c_{T+1}\right) \\
& =U_{T+1}\left(b_{T+1}\right)
\end{aligned}
$$

with optimal consumption $\hat{c}_{T+1}\left(b_{T+1}\right)=b_{T+1}$. Similarly, from definitions of $B_{T+1, y_{T}}$ and $C_{T+1}$ we have

$$
\begin{aligned}
B_{T+1, y_{T}}\left(w_{T+1}\right) & =\min _{u_{T+1}=w_{T+1}} C_{T+1}\left(u_{T+1}\right) \\
& =C_{T+1}\left(w_{T+1}\right) \\
& =U_{T+1}^{-1}\left(w_{T+1}\right)
\end{aligned}
$$

Thus,

$$
B_{T+1, y_{T}}^{-1}=\left(U_{T+1}^{-1}\right)^{-1}=U_{T+1}=W_{T+1, y_{T}}
$$

for both $y_{T} \in \Theta_{T}$. 
This lemma tells us that at $t=T+1$, the objectives on the component planner in the planning problem and an agent in the equilibrium utility maximization problem are lined up. Given that there is no income risk, or incentive problem, in period $T+1$, this conclusion is obvious. However, it provides the first necessary step in our backward-induction argument.

Note that this lemma implies that if

$$
b_{T+1}=B_{T+1, y_{T}}\left(w_{T+1}^{*}\right)
$$

for some $y_{T} \in \Theta_{T}$ and $w_{T+1}^{*} \in S\left(\Omega_{T+1, y_{T}}\right)$, then

$$
\begin{aligned}
W_{T+1, y_{T}}\left(b_{T+1}\right) & =w_{T+1}^{*} \\
\hat{c}_{T+1}\left(b_{T+1}\right) & =C_{T+1}\left(u_{t+1}^{*}\left(w_{T+1}^{*}\right)\right) .
\end{aligned}
$$

Intuitively, Lemma 3 shows that the proposed equilibrium model attains the implementation of the optimal allocation at date $T+1$ : If the distribution of claims $b_{T+1}$ is "right," agents behavior (i.e., consumption) will be consistent with what the component planner would recommend, i.e., will be efficient. Again, this conclusion is obvious in period $T+1$, because there is no income risk or private effort at this date. Our next result provides the same conclusion for all dates $t=1, \ldots, T$, at which the trade-off between incentives and insurance makes this conclusion non-trivial, and gives rise to optimal market and bankruptcy arrangements.

Proposition 2 Fix a pair $\left(t, y_{t-1}\right) \in\{1, \ldots, T\} \times \Theta_{t-1}$. Under bankruptcy rules $\left(f_{t}, g_{t}\right)$ given in (18)-(20), if

$$
W_{t+1, y_{t}}=B_{t+1, y_{t}}^{-1}
$$

for both $y_{t} \in \Theta_{t}$, then

$$
W_{t, y_{t-1}}=B_{t, y_{t-1}}^{-1}
$$

Moreover, for all $b_{t} \in B_{t, y_{t-1}}\left(\Omega_{t, y_{t-1}}\right)$, equilibrium individual policies $\hat{x}_{t, y_{t-1}}, \hat{c}_{t, y_{t-1}}, \hat{b}_{t+1, y_{t-1}}$ satisfy

$$
\begin{aligned}
\hat{x}_{t, y_{t-1}}\left(b_{t}\right) & =X_{t}\left(v_{t}^{*}\left(B_{t, y-1}^{-1}\left(b_{t}\right), y_{t-1}\right)\right) \\
\hat{c}_{t, y_{t-1}}\left(b_{t}\right) & =C\left(u_{t}^{*}\left(B_{t, y-1}^{-1}\left(b_{t}\right), y_{t-1}\right)\right) \\
\hat{b}_{t+1, y_{t-1}}\left(b_{t}, y_{t}\right) & =B_{t+1, y_{t}}\left(w_{t+1}^{*}\left(B_{t, y_{t-1}}^{-1}\left(b_{t}\right), y_{t-1}, y_{t}\right)\right),
\end{aligned}
$$

for $y_{t} \in \Theta_{t}$.

It is clear that proof of Theorem 1 follows from Lemma 4 and Proposition 2. Intuitively, the market arrangement with unsecured credit and bankruptcy achieves implementation of the private- 
information optimum because it provides a restricted amount of individual-state-contingent insurance opportunities to the agents. How restricted these opportunities must be to implement the optimum follows from the incentives requirements. The implementation of these restrictions is achieved through the appropriately chosen bankruptcy asset exemption level for each level of wealth and last-period's income level. Since this mechanism solves the incentive problem, the over-selfinsurance problem vanishes: agents never want to over-accumulate claims, as these will effectively collateralize their unsecured debt, which limits the amount of truly unsecured debt they can use for insurance purposes.

We now turn to proving Proposition 2, which provides the key argument of our implementation result.

Proof of Proposition 2 The proof is constructive. We propose a set of consumer behavior policies and intermediaries' choices and show that, under the assumption of the lemma, they are consistent with equilibrium.

For the consumers, the proposed equilibrium policies are as follows: effort $\hat{x}_{t, y_{t-1}}\left(b_{t}\right)$ as given in (24), consumption $\hat{c}_{t, y_{t-1}}\left(b_{t}\right)$ given in (25), the unsecured borrowing and saving policies given by, respectively,

$$
\begin{aligned}
\hat{h}_{t, y_{t-1}}\left(b_{t}\right) & =\hat{c}_{t, y_{t-1}}\left(b_{t}\right)+\bar{s}_{t, y_{t-1}}\left(b_{t}\right)-b_{t}, \\
\hat{s}_{t, y_{t-1}}\left(b_{t}\right) & =\bar{s}_{t, y_{t-1}}\left(b_{t}\right)
\end{aligned}
$$

consumer default policy given by

$$
\begin{aligned}
& \hat{d}_{t, y_{t-1}}\left(b_{t}, \theta_{t}^{H}\right)=0 \\
& \hat{d}_{t, y_{t-1}}\left(b_{t}, \theta_{t}^{L}\right)=1
\end{aligned}
$$

and claims purchases $\hat{b}_{t+1, y_{t-1}}\left(b_{t}, y_{t}\right)$ as given in (26).

For the intermediaries: the pricing schedule $R_{t, y_{t-1}}\left(\cdot, b_{t}\right)$ given by

$$
R_{t, y_{t-1}}\left(h_{t}, b_{t}\right)=\left\{\begin{array}{ccc}
1 / \pi_{t}\left(\theta_{t}^{H} \mid 1, y_{t-1}\right) & \text { if } & h_{t} \leq \bar{h}_{t, y_{t-1}}\left(b_{t}\right) \\
+\infty & \text { if } & h_{t}>\bar{h}_{t, y_{t-1}}\left(b_{t}\right)
\end{array}\right.
$$

with

$$
\bar{h}_{t, y_{t-1}}\left(b_{t}\right)=C\left(u_{t}^{*}\left(B_{t, y-1}^{-1}\left(b_{t}\right), y_{t-1}\right)\right)+\bar{s}_{t, y_{t-1}}\left(b_{t}\right)-b_{t},
$$


and expectations

$$
\begin{aligned}
h_{t, y_{t-1}}^{e}\left(b_{t}\right) & =\bar{h}_{t, y_{t-1}}\left(b_{t}\right), \\
D_{t, y_{t-1}}^{e}\left(b_{t}\right) & =\pi_{t}\left(\theta_{t}^{L} \mid 1, y_{t-1}\right), \\
\gamma_{t, y_{t-1}}^{e}\left(b_{t}\right) & =0 .
\end{aligned}
$$

We need to show that the proposed consumer policies, intermediaries' pricing and expectations are consistent with equilibrium conditions 1- 3 of Definition 1.

We start with the expectation consistency conditions 3. Substituting the proposed equilibrium consumers' policies, we directly obtain, for every $b_{t} \in B_{t, y_{t-1}}\left(S\left(\Omega_{t, y_{t-1}}\right)\right)$,

$$
\begin{aligned}
h_{t, y_{t-1}}^{e}\left(b_{t}\right) & =C\left(u_{t}^{*}\left(B_{t, y-1}^{-1}\left(b_{t}\right), y_{t-1}\right)\right)+\bar{s}_{t, y_{t-1}}\left(b_{t}\right)-b_{t} \\
& =\hat{c}_{t, y_{t-1}}\left(b_{t}\right)+\bar{s}_{t, y_{t-1}}\left(b_{t}\right)-b_{t} \\
& =\hat{h}_{t, y_{t-1}}\left(b_{t}\right) \\
D_{t, y_{t-1}}^{e}\left(b_{t}\right) & =\pi_{t}\left(\theta_{t}^{L} \mid 1, y_{t-1}\right) \\
& =\pi_{t}\left(\theta_{t}^{L} \mid 1, y_{t-1}\right) 1+\pi_{t}\left(\theta_{t}^{H} \mid 1, y_{t-1}\right) 0 \\
& =\sum_{y_{t} \in \Theta_{t}} \pi_{t}\left(y_{t} \mid x_{t, y_{t-1}}\left(b_{t}\right), y_{t-1}\right) \hat{d}_{t, y_{t-1}}\left(b_{t}\right),
\end{aligned}
$$

which means that the loan demand and default rate expectations are consistent with the proposed equilibrium agent behavior. Also, under the exemption rule $g_{t}$ given in (19)-(20), .the amount of assets seized in equilibrium in bankruptcy from debtors of type $y_{t-1}, b_{t}$ is

$$
\begin{aligned}
g_{t, y_{t-1}}\left(\hat{s}_{t, y_{t-1}}\left(b_{t}\right)\right) & =\max \left\{\hat{s}_{t, y_{t-1}}\left(b_{t}\right)-\bar{s}_{t, y_{t-1}}\left(b_{t}\right), 0\right\} \\
& =\max \left\{\bar{s}_{t, y_{t-1}}\left(b_{t}\right)-\bar{s}_{t, y_{t-1}}\left(b_{t}\right), 0\right\} \\
& =0,
\end{aligned}
$$

which means that the recovery rate expectation $\gamma_{t, y_{t-1}}^{e}\left(b_{t}\right)=0$ is consistent with agents' equilibrium behavior, as well. 
Checking the zero-profit condition for loans of type $y_{t-1}, b_{t}$, we get

$$
\begin{aligned}
\Pi_{t, y_{t-1}, b_{t}}^{e} & =\left[-1+\left(1-D_{t, y_{t-1}}^{e}\left(b_{t}\right)\right) R_{t, y_{t-1}}\left(h_{t, y_{t-1}}^{e}\left(b_{t}\right), b_{t}\right)+D_{t, y_{t-1}}^{e}\left(b_{t}\right) \gamma_{t, y_{t-1}}^{e}\left(b_{t}\right)\right] h_{t, y_{t-1}}^{e}\left(b_{t}\right) \\
& =\left[-1+\left(1-\pi_{t}\left(\theta_{t}^{L} \mid 1, y_{t-1}\right)\right) \frac{1}{\pi_{t}\left(\theta_{t}^{H} \mid 1, y_{t-1}\right)}+\pi_{t}\left(\theta_{t}^{L} \mid 1, y_{t-1}\right) 0\right] h_{t, y_{t-1}}^{e}\left(b_{t}\right) \\
& =[-1+1+0] h_{t, y_{t-1}}^{e}\left(b_{t}\right) \\
& =0
\end{aligned}
$$

for every $b_{t} \in B_{t, y_{t-1}}\left(\Omega_{t, y_{t-1}}\right)$.

All that remains to be shown is that the proposed agents' behavior policies are consistent with agents' utility maximization under the continuation value functions (23), unsecured debt pricing schedules (27) and bankruptcy rules $\left(f_{t}, g_{t}\right)$ given in (18)-(20).

We first demonstrate that the proposed behavior is budget-feasible for each $b_{t} \in B_{t, y_{t-1}}\left(S\left(\Omega_{t, y_{t-1}}\right)\right)$. Straightforward substitution of the proposed equilibrium policies to the budget constraints (15a)(15e) shows it directly, except for the requirement $\hat{h}_{t, y_{t-1}}\left(b_{t}\right) \geq 0$. Under the proposed equilibrium behavior, we have

$$
\hat{h}_{t, y_{t-1}}\left(b_{t}\right)=C\left(u_{t}^{*}\left(B_{t, y-1}^{-1}\left(b_{t}\right), y_{t-1}\right)\right)-\theta_{t}^{L}+q_{t} B_{t+1, \theta_{t}^{L}}\left(w_{t+1}^{*}\left(B_{t, y_{t-1}}^{-1}\left(b_{t}\right), y_{t-1}, \theta_{t}^{L}\right)\right)-b_{t}
$$

for $b_{t} \in B_{t, y_{t-1}}\left(S\left(\Omega_{t, y_{t-1}}\right)\right)$. That the expression on the right-hand side of this equality is positive follows from the fact that, at the recursive optimum, the component planner net delivers resources (provides an insurance payment ex post) to the low-income agents in period $t$. To see this, note that since (by definition)

$$
C\left(u_{t}^{*}\left(w_{t}, y_{t-1}\right)\right)+\sum_{y_{t} \in \Theta_{t}} \pi_{t}\left(y_{t} \mid 1, y_{t-1}\right)\left\{-y_{t}+q_{t} B_{t+1, y_{t}}\left(w_{t+1}^{*}\left(w_{t}, y_{t-1}, y_{t}\right)\right)\right\}-B_{t, y_{t-1}}\left(w_{t}\right)=0
$$

inequality (6) implies

$$
C\left(u_{t}^{*}\left(w_{t}, y_{t-1}\right)\right)-\theta_{t}^{L}+q_{t} B_{t+1, \theta_{t}^{L}}\left(w_{t+1}^{*}\left(w_{t}, y_{t-1}, \theta_{t}^{L}\right)\right)-B_{t, y_{t-1}}\left(w_{t}\right) \geq 0
$$

for all $w_{t} \in S\left(\Omega_{t, y_{t-1}}\right)$, i.e., $\hat{h}_{t, y_{t-1}}\left(B_{t, y_{t-1}}\left(w_{t}\right)\right) \geq 0$ for all $\left.w_{t} \in S\left(\Omega_{t, y_{t-1}}\right)\right)$.

We must demonstrate now that the proposed choices are indeed optimal in the utility maximization problem, i.e., that there does not exist a budget feasible plan that yields more utility than the proposed equilibrium policies. The standard argument for showing that would simply examine the first-order conditions (FOC). The maximization problem at hand, however, has a non-convex budget set. We handle the non-convexity in the following way: we divide the budget set into several 
subsets, each of which is given by linear inequalities. The problem of overall utility maximization is split into the several problems of maximization over the convex subsets. In each of these subsets, we use the standard FOC-based argument. The proposed equilibrium behavior dominates the solutions to each of the sub-problems, and thus it is an overall solution to the utility maximization problem.

We start out by examining the set of default plans available to the agents. Under the eligibility rule (18) choosing $d\left(\theta_{t}^{H}\right)$ is not budget-feasible. Thus, there are only two budget-feasible default plans for agents of all wealth levels $b_{t}$ :

$$
\left(d\left(\theta_{t}^{H}\right), d\left(\theta_{t}^{L}\right)\right)=(0,0)
$$

or

$$
\left(d\left(\theta_{t}^{H}\right), d\left(\theta_{t}^{L}\right)\right)=(0,1)
$$

The default premium $R_{t, y_{t-1}}\left(h, b_{t}\right)>1$ implies that if $d\left(\theta_{t}^{L}\right)=0$, then $h=0$, i.e., if an agent plans to never default, borrowing in the unsecured instrument is a waste. To see it, note that under the no-default plan (28), the budget constraints (15a)-(15e) reduce to

$$
\begin{aligned}
c+s & =b_{t}+h \\
q_{t} b^{\prime}\left(y_{t}\right) & =y_{t}+s-R_{t, y_{t-1}}\left(h, b_{t}\right) h
\end{aligned}
$$

for $y_{t} \in \Theta_{t}$. Given that agents' continuation value $W_{t+1, y_{t}}$ is increasing in $b^{\prime}\left(y_{t}\right)$, any choice of $c, s$, $h$ and $b^{\prime}\left(y_{t}\right)$, such that $h>0$ is strictly dominated by the feasible choice $\tilde{c}=c, \tilde{s}=s-h, \tilde{h}=0$, and

$$
\begin{aligned}
\tilde{b}^{\prime}\left(y_{t}\right) & =q_{t}^{-1}\left(y_{t}+\tilde{s}\right) \\
& =q_{t}^{-1}\left(y_{t}+s-h\right) \\
& >q_{t}^{-1}\left(y_{t}+s-R_{t, y_{t-1}}\left(h, b_{t}\right) h\right) \\
& =b^{\prime}\left(y_{t}\right)
\end{aligned}
$$

for $y_{t} \in \Theta_{t}$. We thus have that, under the proposed equilibrium pricing, the best allocation that agents can individually obtain using the no-default plan (28) coincides with the best allocation they obtain under self-insurance. Given that self-insurance is inefficient in the environment at hand, the proposed equilibrium behavior dominates any individual plan that does not involve default in the low income state.

We now consider deviations from the proposed equilibrium behavior that use the other feasible default plan (29). We first prove the following lemma.

Lemma 5 For any $b_{t} \in B_{t, y_{t-1}}\left(\Omega_{t, y_{t-1}}\right)$, under the proposed equilibrium pricing schedules and bank- 
ruptcy rules, conditional on $x_{t}=1$, the proposed equilibrium policies $\hat{c}_{t, y_{t-1}}, \hat{h}_{t, y_{t-1}}, \hat{s}_{t, y_{t-1}}, \hat{b}_{t+1, y_{t-1}}$ and the default plan (29) solve the consumer utility maximization problem.

\section{Proof In Appendix}

Note that, since the allocation of consumption that results under the individual policies $\hat{c}_{t, y_{t-1}}$, $\hat{h}_{t, y_{t-1}}, \hat{s}_{t, y_{t-1}}, \hat{b}_{t+1, y_{t-1}}$ coincides with optimum, it is true, by Proposition 1, that agents are both insurance- and savings-constrained in equilibrium, i.e., at the solution to their individual utility maximization problems. What does, then, prevent them from using the asset markets from trading away from this allocation? The answer is in the proof of our Lemma 5. Key are the binding constraints imposed by the asset exemption limit $\bar{s}_{t, y_{t-1}}$ and the unsecured credit limit $\bar{h}_{t, y_{t-1}}$. In the proposed equilibrium mechanism, agents transfer resources to their low-income state $y_{t}=\theta_{t}^{L}$ via (intra-period) wealth $s_{t}$, to the extent that $s_{t}$ is exempt in bankruptcy. Hence, under the default plan (29), the asset exemption level $\bar{s}_{t, y_{t-1}}$ limits the amount that can be transferred in this way, which implements the constraint (13). The constraint (12), in turn, is implemented by the credit limit $\bar{h}_{t, y_{t-1}}$. Given that agents want to choose the maximal amount of intra-period savings $s=$ $\bar{s}_{t, y_{t-1}}$ for the purposes of increasing wealth $b^{\prime}\left(\theta_{t}^{L}\right)$, the only way to increase $c$ is to increase $h$, as by (15b), we have

$$
c+\bar{s}_{t, y_{t-1}}=b_{t}+h .
$$

The credit limit $\bar{h}_{t, y_{t-1}}$ makes this impossible, and hence implements (13) in equilibrium.

By this Lemma 5, we know that the proposed equilibrium behavior is individually optimal for the agents (under proposed equilibrium pricing and bankruptcy rules) conditional on high effort $x_{t}=1$. Consider now the following lemma, which demonstrates that the same conclusion is true conditional on low effort $x_{t}=0$.

Lemma 6 For any $b_{t} \in B_{t, y_{t-1}}\left(\Omega_{t, y_{t-1}}\right)$, under the proposed equilibrium pricing schedules and bankruptcy rules, conditional on $x_{t}=0$, the proposed equilibrium policies $\hat{c}_{t, y_{t-1}}, \hat{h}_{t, y_{t-1}}, \hat{s}_{t, y_{t-1}}, \hat{b}_{t+1, y_{t-1}}$ and the default plan (29) solve the consumer utility maximization problem.

Intuition for this lemma, is derives from Lemma 5. If agents shirk, i.e., choose $x_{t}=0$, they are even more likely to find themselves in the low-income state $y_{t}=\theta_{t}^{L}$. Hence, they want even "more badly" to use asset markets to insure/hedge this risk. By (12) and (13), this means that they desire to transfer resources from the end-of-period state $y_{t}=\theta_{t}^{H}$ to the beginning of period $t$, and from the beginning of period $t$ to the end-of-period state $y_{t}=\theta_{t}^{L}$. But, as we demonstrate in Lemma 5 , the asset exemption limit $\bar{s}_{t, y_{t-1}}$ and the unsecured credit limit $\bar{h}_{t, y_{t-1}}$ make such transfers impossible in equilibrium (beyond amounts consistent with optimum). Thus, the asset market structure available to the agents makes asset market deviations form the proposed equilibrium asset markets position undesirable under both high effort and shirking. 
By Lemma 5 and Lemma 6, we have that agents find it optimal to follow the proposed consumption and asset markets policies (under default plan (29)) both if they plan to work and not work hard. Thus, the utility of the proposed consumption $U\left(\hat{c}_{t, y_{t-1}}\left(b_{t}\right)\right)$ and the continuation val-

ues for end-of-period wealth $W_{t+1, y_{t}}\left(\hat{b}_{t+1, y_{t-1}}\left(b_{t}, y_{t}\right)\right)$ implemented under either effort level coincide with the optimal utility level $u_{t}^{*}\left(w_{t}, y_{t-1}\right)$ and utility continuation values $w_{t+1}^{*}\left(w_{t}, y_{t-1}, y_{t}\right)$ for $w_{t}=B_{t, y_{t-1}}^{-1}\left(b_{t}\right)$, which are delivered at the solution to the component planning problem. Since high effort satisfies the incentive compatibility requirement (3), it follows that in equilibrium, too, agents (weakly) prefer to exert the high effort $x_{t}=1$.

This completes the proof of Proposition 2.

\subsection{Remarks}

1. Both the asset exemption limit $\bar{s}_{t, y_{t-1}}$ and the discontinuity of unsecured credit pricing at the credit limit $\bar{h}_{t, y_{t-1}}$ are necessary. If either of them were absent from the restrictions on the space of asset market deviations available to the agents, agents would trade away from the optimal allocation of consumption and wealth. In addition, given that agents are indifferent with respect to the amount of effort they exert in equilibrium and the benefit of such a trade-away is stronger under the low effort level, agents' most profitable deviation plan would include shirking. Thus, both of these restrictions are necessary to prevent over-insurance and induce high effort in equilibrium.

2. The discontinuity of unsecured credit pricing at the credit limit $\bar{h}_{t, y_{t-1}}$ is necessary. However, the hike in pricing does not have to be as extreme as the proposed credit denial $\left[R_{t, y_{t-1}}\left(h, b_{t}\right)=+\infty\right.$ for $\left.h>\bar{h}_{t, y_{t-1}}\left(b_{t}\right)\right]$. This off-equilibrium price may be chosen to be large but finite. Proving this, however, requires going through additional cases in the consumer utility maximization problem, which only makes the proofs longer. 


\section{Appendix}

\section{Proof of Lemma 2}

Fix an arbitrary $\left(t, y_{t-1}\right) \in\{1, \ldots, T\} \times \Theta_{t-1}$ and $w_{t} \in S\left(\Omega_{t, y-1}\right)$. Inequality (5) follows from the TIC constraint (3), Assumption 1, the fact that effort carries disutility, $V_{t}(1)>V_{t}(0)$ for all $t=1, \ldots, T$, and from (1), i.e., the fact that effort is (strictly) productive. It also follows that the TIC constraint (3) binds.

Since TIC binds at the solution with the recommendation of high effort (i.e., under Assumption 1 ), the recommendation of low effort $x_{t}\left(w_{t}, y_{t-1}\right)=0$ satisfies the TIC, as well. Under this recommendation, the PK constraint (4) is satisfied also, as either side of the binding TIC constraint equals $w_{t}-u_{t}^{*}\left(w_{t}, y_{t-1}\right)$. Note that if (6) is violated, by (1),

$$
\begin{aligned}
B_{t, y_{t-1}}(w) & =C\left(u_{t}^{*}\left(w_{t}, y_{t-1}\right)\right)+\sum_{y_{t} \in \Theta_{t}} \pi_{t}\left(y_{t} \mid 1, y_{t-1}\right)\left\{-y_{t}+q_{t} B_{t+1, y_{t}}\left(w_{t+1}^{*}\left(w_{t}, y_{t-1}, y_{t}\right)\right)\right\} \\
& >C\left(u_{t}^{*}\left(w_{t}, y_{t-1}\right)\right)+\sum_{y_{t} \in \Theta_{t}} \pi_{t}\left(y_{t} \mid 0, y_{t-1}\right)\left\{-y_{t}+q_{t} B_{t+1, y_{t}}\left(w_{t+1}^{*}\left(w_{t}, y_{t-1}, y_{t}\right)\right)\right\},
\end{aligned}
$$

which contradicts Assumption 1. Thus, (6) holds.

\section{Proof of Lemma 3}

Note first that the solution to the component planning problem at $T+1$ is immediate:

$$
B_{T+1, y_{T}}(w)=C_{T+1}(w)
$$

independently of $y_{T}$. Because $U_{T+1}$ is $C^{2}$, strictly increasing and concave, $B_{T+1, y_{T}}$ is $C^{2}$, strictly increasing convex.

Consider now the cost function $B_{T, y_{T-1}}$. Since $B_{T+1, y_{T}}$ is strictly convex, $B_{T, y_{T-1}}$ is the value of a minimization problem with a strictly convex objective and linear constraints. By strict convexity, his problem has a unique solution that can be characterized by first-order and envelope conditions. The functions $B_{T, y_{T-1}}$ are also strictly convex. Proceeding backwards, we have that all functions $B_{t, y_{t-1}}$ are strictly increasing and convex.

and can be characterized by first-order and envelope conditions.

Fix an arbitrary $t \in\{1, \ldots, T\}$ and $w_{t}$. To show (7), note that the value $\hat{u}$ defined as

$$
\hat{u}=u_{t}^{*}\left(w_{t}, \theta_{t-1}^{L}\right)-\beta\left(w_{t+1}^{*}\left(w_{t}, \theta_{t}^{L}, \theta_{t}^{H}\right)-w_{t+1}^{*}\left(w_{t}, \theta_{t}^{L}, \theta_{t}^{L}\right)\right)\left(\pi_{t}\left(\theta_{t}^{H} \mid 1, \theta_{t-1}^{H}\right)-\pi_{t}\left(\theta_{t}^{H} \mid 1, \theta_{t-1}^{H}\right)\right)
$$

satisfies $\hat{u} \leq u_{t}^{*}\left(w_{t}, \theta_{t-1}^{L}\right)$ because the terms in parentheses are positive by (5) and (2), respectively. 
Also, it is easy to check (using (2) again) that the utility assignment $\hat{u}$ and the continuation value assignment $w_{t+1}^{*}\left(w_{t}, \theta_{t}^{L}, y_{t}\right)$ for $y_{t} \in \Theta_{t}$, are feasible in the constraint set of the minimization problem defining $B_{t, \theta_{t-1}^{H}}\left(w_{t}\right)$. Thus

$$
\begin{aligned}
B_{t, \theta_{t-1}^{H}}\left(w_{t}\right) & \leq C(\hat{u})+\sum_{y_{t} \in \Theta_{t}} \pi_{t}\left(y_{t} \mid 1, \theta_{t-1}^{H}\right)\left\{-y_{t}+q_{t} B_{t+1, y_{t}}\left(w_{t+1}^{*}\left(w_{t}, \theta_{t-1}^{L}, y_{t}\right)\right)\right\} \\
& \leq C\left(u_{t}^{*}\left(w_{t}, \theta_{t-1}^{L}\right)\right)+\sum_{y_{t} \in \Theta_{t}} \pi_{t}\left(y_{t} \mid 1, \theta_{t-1}^{L}\right)\left\{-y_{t}+q_{t} B_{t+1, y_{t}}\left(w_{t+1}^{*}\left(w_{t}, \theta_{t-1}^{L}, y_{t}\right)\right)\right\} \\
& =B_{t, \theta_{t-1}^{L}}\left(w_{t}\right),
\end{aligned}
$$

where the second inequality follows from $\hat{u} \leq u_{t}^{*}\left(w_{t}, \theta_{t-1}^{L}\right),(6)$ and (2).

Differentiability: Consider the difference $B_{t, y_{t-1}}\left(w_{t}\right)-B_{t, y_{t-1}}\left(w_{t}-\varepsilon\right)$ for some $w_{t}$ and $\varepsilon>0$. Noting that the policies $u_{t}^{*}\left(w_{t}-\varepsilon, y_{t-1}\right)+\varepsilon$ and $w_{t+1}^{*}\left(w_{t}-\varepsilon, y_{t-1}, y_{t}\right)$ for $y_{t} \in \Theta_{t}$ are feasible in the minimization problem defining $B_{t, y_{t-1}}\left(w_{t}\right)$, we get

$$
B_{t, y_{t-1}}\left(w_{t}\right)-B_{t, y_{t-1}}\left(w_{t}-\varepsilon\right) \leq C\left(u_{t}^{*}\left(w_{t}-\varepsilon, y_{t-1}\right)+\varepsilon\right)-C\left(u_{t}^{*}\left(w_{t}-\varepsilon, y_{t-1}\right)\right) .
$$

Also, since the policies $u_{t}^{*}\left(w_{t}, y_{t-1}\right)-\varepsilon$ and $w_{t+1}^{*}\left(w_{t}, y_{t-1}, y_{t}\right)$ for $y_{t} \in \Theta_{t}$ are feasible in the minimization problem defining $B_{t, y_{t-1}}\left(w_{t}-\varepsilon\right)$, we get

$$
B_{t, y_{t-1}}\left(w_{t}\right)-B_{t, y_{t-1}}\left(w_{t}-\varepsilon\right) \geq C\left(u_{t}^{*}\left(w_{t}, y_{t-1}\right)\right)-C\left(u_{t}^{*}\left(w_{t}, y_{t-1}\right)-\varepsilon\right)
$$

Dividing by $\varepsilon$, we get

$$
\begin{aligned}
\frac{C\left(u_{t}^{*}\left(w_{t}, y_{t-1}\right)\right)-C\left(u_{t}^{*}\left(w_{t}, y_{t-1}\right)-\varepsilon\right)}{\varepsilon} & \leq \frac{B_{t, y_{t-1}}\left(w_{t}\right)-B_{t, y_{t-1}}\left(w_{t}-\varepsilon\right)}{\varepsilon} \\
& \leq \frac{C\left(u_{t}^{*}\left(w_{t}-\varepsilon, y_{t-1}\right)+\varepsilon\right)-C\left(u_{t}^{*}\left(w_{t}-\varepsilon, y_{t-1}\right)\right)}{\varepsilon}
\end{aligned}
$$

Taking the limit $\varepsilon \rightarrow 0$, we get that $B_{t, y_{t-1}}^{\prime}\left(w_{t}\right)$ exists with

$$
B_{t, y_{t-1}}^{\prime}\left(w_{t}\right)=C^{\prime}\left(u_{t}^{*}\left(w_{t}, y_{t-1}\right)\right)
$$

We can now further characterize the cost functions $B_{t, y_{t-1}}$ by using the first-order conditions. These are, for every state $\left(t, y_{t-1}\right) \in\{1, \ldots, T\} \times \Theta_{t-1}$ and value $w_{t} \in S\left(\Omega_{t, y-1}\right)$, as follows

$$
\begin{aligned}
C^{\prime}\left(u_{t}^{*}\left(w_{t}, y_{t-1}\right)\right) & =\mu_{t, y_{t-1}, w_{t}}, \\
B_{t+1, y_{t}}^{\prime}\left(w_{t+1}^{*}\left(w_{t}, y_{t-1}, y_{t}\right)\right) q_{t} \beta^{-1} & =\lambda_{t, y_{t-1}, w_{t}}\left(1-L R_{t}\left(y_{t} \mid y_{t-1}\right)\right)+\mu_{t, y_{t-1}, w_{t}},
\end{aligned}
$$


for $y_{t} \in \Theta_{t}$, where $\lambda_{t, y_{t-1}, w_{t}}$ is the Lagrange multiplier on the TIC constraint, $\mu_{t, y_{t-1}, w_{t}}>0$ is the Lagrange multiplier on the $\mathrm{PK}$ constraint, and $L R_{t}\left(y_{t} \mid y_{t-1}\right)$ is the conditional likelihood ratio, given by

$$
L_{t}\left(y_{t} \mid y_{t-1}\right)=\frac{\pi_{t}\left(y_{t} \mid 0, y_{t-1}\right)}{\pi_{t}\left(y_{t} \mid 1, y_{t-1}\right)}
$$

The envelope condition, for every state $\left(t, y_{t-1}\right) \in\{1, \ldots, T\} \times \Theta_{t-1}$ and value $w_{t} \in S\left(\Omega_{t, y-1}\right)$, is

$$
B_{t, y_{t-1}}^{\prime}\left(w_{t}\right)=\mu_{t, y_{t-1}, w_{t}}
$$

The conditional expectation of the likelihood ratio, under optimal effort $x_{t}^{*}=1$ is equal 1 :

$$
\begin{aligned}
\sum_{y_{t} \in \Theta_{t}} \pi_{t}\left(y_{t} \mid 1, y_{t-1}\right) L R_{t}\left(y_{t} \mid y_{t-1}\right) & =\sum_{y_{t} \in \Theta_{t}} \pi_{t}\left(y_{t} \mid 1, y_{t-1}\right) \frac{\pi_{t}\left(y_{t} \mid 0, y_{t-1}\right)}{\pi_{t}\left(y_{t} \mid 1, y_{t-1}\right)} \\
& =1
\end{aligned}
$$

Since effort is productive, i.e., (1), we thus have

$$
L R_{t}\left(\theta_{t}^{H} \mid y_{t-1}\right)<1<L R_{t}\left(\theta_{t}^{L} \mid y_{t-1}\right)
$$

for all $y_{t-1} \in \Theta_{t-1}$.

Note that Assumption 1 implies that $\lambda_{t, w_{t}, y_{t-1}}>0$ for all $\left(t, y_{t-1}\right) \in\{1, \ldots, T\} \times \Theta_{t-1}$ and $w_{t} \in S\left(\Omega_{t, y-1}\right)$.

Condition (8) of Lemma 2 follows directly from (31) and (33). Inequalities (9) and (10) follow from (32) with (33) and (35). Condition (11) follows by adding (32) over $y_{t} \in \Theta_{t}$ and using (34).

\section{Proof of Lemma 5}

Under the assumptions of the lemma, the problem of a consumer of type $y_{t-1}, b_{t}$ reduces to

$$
\max _{c, h, s, b^{\prime}\left(y_{t}\right)} V_{t}(1)+U(c)+\beta \sum_{y_{t} \in \Theta_{t}} \pi_{t}\left(y_{t} \mid 1, y_{t-1}\right) W_{t+1, y_{t}}\left(b^{\prime}\left(y_{t}\right)\right)
$$


subject to the budget constraints

$$
\begin{aligned}
h & \geq 0, \\
h & \leq \bar{h}_{t, y_{t-1}}\left(b_{t}\right), \\
c+s & =b_{t}+h, \\
q_{t} b^{\prime}\left(\theta_{t}^{H}\right) & =\theta_{t}^{H}+s-\frac{1}{\pi_{t}\left(\theta_{t}^{H} \mid 1, y_{t-1}\right)} h, \\
q_{t} b^{\prime}\left(\theta_{t}^{L}\right) & =\theta_{t}^{L}+s-\max \left\{s-\bar{s}_{t, y_{t-1}}\left(b_{t}\right), 0\right\} \\
& =\theta_{t}^{L}+\min \left\{s, \bar{s}_{t, y_{t-1}}\left(b_{t}\right)\right\} .
\end{aligned}
$$

Note that the constraint $h \leq \bar{h}_{t, y_{t-1}}\left(b_{t}\right)$ is imposed by the proposed equilibrium pricing schedule $R_{t, y_{t-1}}\left(h, b_{t}\right)$. If an agent were to choose to hold $h>\bar{h}_{t, y_{t-1}}\left(b_{t}\right)$, his obligation would be very large (infinite) in the high-income state $y_{t}=\theta_{t}^{H}$, which is realized with a strictly positive probability (at both effort levels, in fact). Thus $h>\bar{h}_{t, y_{t-1}}\left(b_{t}\right)$ cannot be optimal under pricing $R_{t, y_{t-1}}\left(h, b_{t}\right){ }^{6}$ Hence, we can restrict attention to $h$ not exceeding $\bar{h}_{t, y_{t-1}}\left(b_{t}\right)$.

Let $\Gamma$ denote the budget set given by (37)-(41). $\Gamma$ is not convex, due to (41). We will now divide $\Gamma$ into two convex subsets as follows. Let $\Gamma_{1}$ be given by

$$
\begin{aligned}
h & \geq 0, \\
h & \leq \bar{h}_{t, y_{t-1}}\left(b_{t}\right), \\
s & \leq \bar{s}_{t, y_{t-1}}\left(b_{t}\right), \\
c+s & =b_{t}+h, \\
q_{t} b^{\prime}\left(\theta_{t}^{H}\right) & =\theta_{t}^{H}+s-\frac{1}{\pi_{t}\left(\theta_{t}^{H} \mid 1, y_{t-1}\right)} h, \\
q_{t} b^{\prime}\left(\theta_{t}^{L}\right) & =\theta_{t}^{L}+s .
\end{aligned}
$$

\footnotetext{
${ }^{6}$ For the proof to work, the pricing does not have be that stark. A jump in the interest rate is required, but not necessarily that large. With this pricing, however, the proof is simpler. See Remark X on page Y for more discussion.
} 
Let $\Gamma_{2}$ be given by

$$
\begin{aligned}
h & \geq 0, \\
h & \leq \bar{h}_{t, y_{t-1}}\left(b_{t}\right), \\
s & \geq \bar{s}_{t, y_{t-1}}\left(b_{t}\right), \\
c+s & =b_{t}+h, \\
q_{t} b^{\prime}\left(\theta_{t}^{H}\right) & =\theta_{t}^{H}+s-\frac{1}{\pi_{t}\left(\theta_{t}^{H} \mid 1, y_{t-1}\right)} h, \\
q_{t} b^{\prime}\left(\theta_{t}^{L}\right) & =\theta_{t}^{L}+\bar{s}_{t, y_{t-1}}\left(b_{t}\right) .
\end{aligned}
$$

Both $\Gamma_{1}$ and $\Gamma_{2}$ are convex, as they are given by linear equality and inequality constraints. Also, the union of $\Gamma_{1}$ and $\Gamma_{2}$ is $\Gamma$. The vector of choices for $h, s, c, b^{\prime}\left(\theta_{t}^{H}\right), b^{\prime}\left(\theta_{t}^{L}\right)$ prescribed by the proposed equilibrium policies evaluated at $b_{t}$, denote this vector by $z^{e}$, is feasible in both $\Gamma_{1}$ and $\Gamma_{2}$. Define now two auxiliary utility maximization problems as follows: 1) maximize (36) over $\Gamma_{1}$, and 2) maximize (36) over $\Gamma_{2}$. In order to show that $z^{e}$ maximizes (36) over $\Gamma$, it is sufficient to show that $z^{e}$ solves both of the two auxiliary maximization problems. Indeed, if there exists in $\Gamma$ a vector $\tilde{z}$ that dominates $z^{e}$ (with respect to the objective (36)), then $z^{e}$ cannot solve both of the two auxiliary problems, as $\tilde{z}$ must be feasible in at least one of them.

By the strict concavity of the objective, and the convexity of the constraint set, it is sufficient to show that $z^{e}$ satisfies the FOCs in each of the two auxiliary problems. In the first sub-problem, they are (ignoring the non-negativity constraint on $h$ ):

$$
U^{\prime}(c) \geq \beta q_{t}^{-1} W_{t+1, \theta_{t}^{H}}^{\prime}\left(b^{\prime}\left(\theta_{t}^{H}\right)\right)
$$

with equality if $h<\bar{h}_{t, y_{t-1}}\left(b_{t}\right)$ and

$$
U^{\prime}(c) \leq \beta q_{t}^{-1} \sum_{y_{t} \in \Theta_{t}} \pi_{t}\left(y_{t} \mid 1, y_{t-1}\right) W_{t+1, y_{t}}^{\prime}\left(b^{\prime}\left(y_{t}\right)\right)
$$

with equality if $s<\bar{s}_{t, y_{t-1}}\left(b_{t}\right)$. Using the inductive assumption (23), and the Inverse Function Theorem, we get that evaluated at the proposed equilibrium values, these sufficient conditions read, irrespectively,

$$
\frac{1}{C^{\prime}\left(u_{t}^{*}\left(w_{t}, y_{t-1}\right)\right)} \geq \beta q_{t}^{-1} \frac{1}{B_{t+1, \theta_{t}^{H}}^{\prime}\left(w_{t+1}^{*}\left(w_{t}, y_{t-1}, \theta_{t}^{H}\right)\right)}
$$

and

$$
\frac{1}{C^{\prime}\left(u_{t}^{*}\left(w_{t}, y_{t-1}\right)\right)} \leq \beta q_{t}^{-1} \sum_{y_{t} \in \Theta_{t}} \pi_{t}\left(y_{t} \mid 1, y_{t-1}\right) \frac{1}{B_{t+1, \theta_{t}^{H}}^{\prime}\left(w_{t+1}^{*}\left(w_{t}, y_{t-1}, y_{t}\right)\right)}
$$


where $w_{t}=B_{t, y_{t-1}}^{-1}\left(b_{t}\right) \in S\left(\Omega_{t, y-1}\right)$. That the first of these conditions is true follows from identity (8) and inequality (10) of Lemma 2. In fact, this condition is satisfied with strict inequality. That the second of these conditions is true follows from identity (8) and an application of Jensen inequality to the equality (11) of Lemma 2 (the martingale property). This condition, as well, is satisfied with strict inequality. Thus, the proposed equilibrium behavior does solve the first auxiliary problem.

The sufficient FOC of the second problem are as follows (ignoring again the non-negativity constraint on $h$ ):

$$
U^{\prime}(c) \geq \beta q_{t}^{-1} W_{t+1, \theta_{t}^{H}}^{\prime}\left(b^{\prime}\left(\theta_{t}^{H}\right)\right)
$$

with equality if $h<\bar{h}_{t, y_{t-1}}\left(b_{t}\right)$ and

$$
U^{\prime}(c) \geq \beta q_{t}^{-1} \pi_{t}\left(\theta_{t}^{H} \mid 1, y_{t-1}\right) W_{t+1, \theta_{t}^{H}}^{\prime}\left(b^{\prime}\left(\theta_{t}^{H}\right)\right)
$$

with equality if $s>\bar{s}_{t, y_{t-1}}\left(b_{t}\right)$. Note that (44) coincides with (42), thus, is satisfied by the proposed equilibrium policies. The second FOC (45) follows directly from (44), as $\pi_{t}\left(\theta_{t}^{H} \mid 1, y_{t-1}\right) \leq 1$. Thus, the proof of the lemma is complete.

\section{Proof of Lemma 6}

Follows the same steps as the proof of Lemma 5. The only difference between the two problems (setting aside the additive component $V_{t}\left(x_{t}\right)$ in the objective) is the probability distribution $\pi_{t}\left(y_{t} \mid x_{t}, y_{t-1}\right)$. The sufficient FO conditions of the first sub-problem (i.e., over the set $\Gamma_{1}$ ) are:

$$
U^{\prime}(c) \geq \beta q_{t}^{-1} \frac{\pi_{t}\left(\theta_{t}^{H} \mid 0, y_{t-1}\right)}{\pi_{t}\left(\theta_{t}^{H} \mid 1, y_{t-1}\right)} W_{t+1, \theta_{t}^{H}}^{\prime}\left(b^{\prime}\left(\theta_{t}^{H}\right)\right)
$$

with equality if $h<\bar{h}_{t, y_{t-1}}\left(b_{t}\right)$ and

$$
U^{\prime}(c) \leq \beta q_{t}^{-1} \sum_{y_{t} \in \Theta_{t}} \pi_{t}\left(y_{t} \mid 0, y_{t-1}\right) W_{t+1, y_{t}}^{\prime}\left(b^{\prime}\left(y_{t}\right)\right)
$$

with equality if $s<\bar{s}_{t, y_{t-1}}\left(b_{t}\right)$. Condition (46) follows from the fact that (42) is satisfied by the proposed equilibrium policies, and the left inequality in (35). Similarly, that the proposed equilibrium policies satisfy (47) follows from (43), (1), and the spread property of the optimum, i.e., (9) and (10).

The sufficient FO conditions of the second sub-problem $\left(\Gamma_{2}\right)$ are:

$$
U^{\prime}(c) \geq \beta q_{t}^{-1} \frac{\pi_{t}\left(\theta_{t}^{H} \mid 0, y_{t-1}\right)}{\pi_{t}\left(\theta_{t}^{H} \mid 1, y_{t-1}\right)} W_{t+1, \theta_{t}^{H}}^{\prime}\left(b^{\prime}\left(\theta_{t}^{H}\right)\right),
$$


with equality if $h<\bar{h}_{t, y_{t-1}}\left(b_{t}\right)$ and

$$
U^{\prime}(c) \geq \beta q_{t}^{-1} \pi_{t}\left(\theta_{t}^{H} \mid 0, y_{t-1}\right) W_{t+1, \theta_{t}^{H}}^{\prime}\left(b^{\prime}\left(\theta_{t}^{H}\right)\right)
$$

with equality if $s>\bar{s}_{t, y_{t-1}}\left(b_{t}\right)$. Condition (48) is the same as (46), thus, is satisfied by the proposed equilibrium. Finally, (49) follows from (45) and (1). 


\section{References}

Albanesi, S., and Ch. Sleet, (2006), Dynamic Optimal Taxation with Private Information, Review of Economic Studies, 73, 1-30.

Athreya, K. (2002), "Welfare Implications of the Bankruptcy Reform Act of 1999," Journal of Monetary Economics, 49, 1567-1595.

Athreya, K. and N. Simpson (2006), "Unsecured Debt with Public Insurance: From Bad to Worse," Journal of Monetary Economics, 53, 797-825.

Atkeson, A., and R.E. Lucas Jr. (1992), "On efficient distribution with private information." Review of Economic Studies 59, 427-453.

Chatterjee, S., D. Corbae, M. Nakajima, J.V. Rios-Rull, (2005), "A quantitative theory of unsecured consumer credit with risk of default." Working Paper, University of Pennsylvania.

Kocherlakota, N., (2005), "Zero expected wealth taxes: A Mirrlees approach to dynamic optimal taxation," Econometrica, 73, 1587-1621.

Li, W. and P. D. Sarte (2006), "U.S. Consumer Bankruptcy Choice: The Importance of General Equilibrium Effects," Journal of Monetary Economics, 53, 613-631.

Livshits, I., J. MacGee, and M. Tertilt (2007), "Consumer Bankruptcy: A Fresh Start," American Economic Review, forthcoming.

Mirrlees, J.A., (1971), "An Exploration in the theory of optimum income taxation," Review of Economic Studies, 38, 175-208. 